\title{
Kamusal Alanlar Arasındaki Mikromobiliteyi Destekleyecek Kişiselleştirilmiş Ulaşım Modeli Önerisi*
}

\author{
Esma Selen Aksoy 1 \\ ORCID: 0000-0002-8373-9737
}

\author{
Şehnaz Cenani ${ }^{2}$ \\ ORCID: 0000-0001-8111-586X
}

\author{
Gülen Çağdaş3 \\ ORCID: 0000-0001-8853-4207
}

\section{Öz}

Kentte bir buluşma noktası olan kamusal alanlar, farklı bireylerin karşılaştıkları ve birlikte zaman geçirdikleri yerlerdir. Bu alanlara ulaşım seçenekleri ise bireylerin değiş̧en taleplerine göre her zaman aynı olmayabilir. Tercihlerin aynı olmaması ve ayn seçeneğe yönlendirilmemesi de kamusal alan kullanımında çeşitliliğin să̆lanması için oldukça önemlidir. Bu nedenle çalışmada, kamusal alanların kent içinde önemli duraklar olduğu kabul edilerek, iki kamusal alan arasında kişiselleştirilmiş bir ulaşım modeli önerilmiştir. Çalışmada yöntem olarak Analitik Hiyerarşi Süreci ve Bayes Ağları kullanılmıştır. Analitik Hiyerarşi Süreci yönteminde değerlendirilecek olan ulaşım seçenekleri, mikromobilite çalışmaları kapsamında ele alınmıştır. Bisiklet, elektrikli scooter ve yürüme eylemi için örnek rotalar oluşturulmuştur. Rotaların tercihini belirleyen kriterler için literatür incelemeleri yapılmış ve eşik değerler çıkarılmıştır. Ancak kullanıcıların farklı tercihlerine göre kriterlerin önemi ve buna bağlı olarak da rotaları uygunluğu da değişebilmektedir. Bu nedenle kriterlerin ă̆ırlığının belirlenmesinde kullanıcı tercihlerinin dinamik değişsenliğini gözlemleyebileceğimiz Bayes Ağlar modele dahil edilmiştir. Kullanıcıların tercihlerine göre, Bayes Ağları ile kriterlerin ağırlıkları belirlenmiş ve bu kriterler Analitik Hiyerarşi Süreci ile değerlendirilmiştir. Bayes Ă̆ları ile kriterlerin ă̆ırlıklarının belirlenmesi Analitik Hiyerarşi Süreci yönteminde verilerin tutarlılı̆̆ıı să̆lamış ve sistemi daha esnek hale getirmiştir.

Anahtar Kelimeler: Çok Kriterli Karar Verme (ÇKKV), Analitik Hiyerarşi Süreci (AHP), Bayes A ğları, Mikromobilite.

\footnotetext{
* Bu makale "5. Kent Araştırmaları Kongresi”"nde aynı başlıkla sunulan bildirinin geliştirilmiş ve hakem sürecinden geçmiş halidir.

${ }^{1}$ Doktora Öğrencisi, İTÜ, E-mail: aksoye@itu.edu.tr

${ }^{2}$ Dr. Öğr. Üye., İstanbul Medipol Üniversitesi, E-mail: sdurmazoglu@medipol.edu.tr

${ }^{3}$ Prof. Dr., İTÜ, E-mail: cagdas@itu.edu.tr

idealkent @ Kent Araştırmaları Dergisi (Journal of Urban Studies)

http://idealkentdergisi.com

Geliş Tarihi Received Date: 24.12.2020 Kabul Tarihi Accepted Date: 01.09.2021
} 


\title{
Personalized Transportation Model Proposal to Support Micromobility Between Public Spaces
}

\author{
Esma Selen Aksoy 4 \\ ORCID: 0000-0002-8373-9737
}

\author{
Şehnaz Cenani ${ }^{5}$ \\ ORCID: 0000-0001-8111-586X
}

\author{
Gülen Çağdaş ${ }^{6}$ \\ ORCID: 0000-0001-8853-4207
}

\begin{abstract}
Public spaces are a meeting point in the city, where different individuals meet and spend time together. Transportation options for these areas may not always be the same due to the changing demands of individuals. It is important that the preferences are not the same and not directed to the same option in order to ensure diversity in the use of public space. For this reason, in the study, a personalized transportation model between two public spaces is proposed. Analytical Hierarchy Process and Bayesian Networks are used as methods in the study. The transportation options that will be evaluated in the Analytical Hierarchy Process method are discussed within the scope of micromobility studies. Sample routes have been created for cycling, electric scooters and walking action. Literature reviews have been made for the criteria determining the choice of routes and threshold values have been removed. However, the importance of the criteria and the suitability of the routes may also change according to the different preferences of the users. For this reason, Bayesian Networks, where we can observe the dynamic variability of user preferences in determining the weight of the criteria, are included in the model.
\end{abstract}

Keywords: Multi Criteria Decision Making, Analytical Hierarchy Process (AHP), Bayesian Networks, Micromobility

\footnotetext{
${ }^{4}$ PhD. Student, İTU, E-mail: aksoye@itu.edu.tr

${ }^{5}$ Asts. Prof., İstanbul Medipol University, E-mail: sdurmazoglu@medipol.edu.tr

${ }_{6}^{6}$ Prof. Dr., İTU, E-mail: cagdas@itu.edu.tr

idealkent @ Kent Araştırmaları Dergisi (Journal of Urban Studies)

http://idealkentdergisi.com

Geliş Tarihi Received Date: 24.12.2020 Kabul Tarihi Accepted Date: 01.09.2021
} 


\section{Giriş}

Kentteki ulaşım sistemleri kentsel mekânı şekillendiren önemli unsurlardır. Yeni sistemlerle birlikte değişen ulaşım alışkanlıkları ise kentlerde yeni ilişkiler üretmektedir. Kamusal alanlar kentteki ilişkilerle biçimlenmekte olan ve kentte yaşayan her bireyin eşit erişim hakkının olduğu karşılaşma noktalarıdır. Gehl (2006)' in de belirttiği gibi kamusal alanların birbiri ile erişilebilirliği, ekolojik yeşil köprülerin oluşması ve sosyal ilişkilerin aktarılması açısından da önemlidir. Ancak kamusal alanlara erişilebilirlik kullanıcıların tercihine göre farklılık gösterebilir ve erişilebilirliğin çeşitlendirilmemesi kamusallığın sürdürülebilirliği açısından problem teşkil edebilmektedir. Bu alanlara ulaşırken kullanıcılara aynı rotaları önermek, kullanıcıların kamusal alana erişim seçeneklerini sınırlamakta ve sosyal ilişkilerin çeşitlenmesinde ve aktarılmasında tektipleşmeye neden olmaktadır. Bir diğer problem ise bu alanların birbiri ile erişiminde çevreci rotaların ön plana çıkarılmamasıdır. Bu nedenle çalışmada, farklı tercihleri olan kullanıcılara kamusal alanlar arasındaki ulaşım için, mikromobiliteyi destekleyen kişiselleştirilmiş bir model önerilmiştir. Mikromobilite terimi, bisiklet paylaşım sistemleri, elektrikli bisikletler ve elektrikli scooterlar gibi çevreye duyarlı bireysel ulaşım modları için kullanılmaktadır (DuPuis, Griess ve Klein, 2019). Mikromobilite araçlarının farklı rotalara uyarlanabilen esnek kullanımı da kent içi ulaşımlarda birçok yarar sağlamaktadır. Bu çalışmada çözüm olarak mikromobilitenin sağladığı esneklik, bireyselleşme ile azalan kamusal alan kullanımını arttırmak için kullanılmıştır. Çalışmanın yönteminde Analitik Hiyerarşi Süreci (AHP), Bayes Ağları ile desteklenmiştir. Çalışmada bireysel tercihlere yönelik bir ulaşım seçimi için mikromobilite araçlarından en çok tercih edilen bisiklet ve escooter seçilmiştir. Yürüme seçeneği de kamusal alanlar arası ulaşımda, rotalardaki kentsel hareketliliği zenginleştireceği ve mevcut rotaların değerlendirilmesi için fayda sağlayacağı düşünülerek, ulaşım seçeneklerine eklenmiştir. Sunulan yöntemin uygulandığı alan çalışması olarak İstanbul, Taksim’de bulunan Gezi Parkı ve Maçka Parkı arasındaki rota seçilmiştir. Bu alan Henri Prost'un, 1940'larda kent için tasarladığı II Nolu Park olarak tasarlanmış bir alandır. Günümüzde parçalanan bu alanın yeşil koridor etkisini sürdürmek ve mikromobilite kavramını değerlendirmek için uygun olacağı düşünülmüştür. 


\section{Yöntem}

Bu çalışmada problem olarak belirlenen; kamusal alana erişim seçeneklerinin sınırlı olması ve kamusal alanların birbiri ile erişiminde çevreci rotaların oluşturulmaması durumu için kişiselleştirilmiş ve mikromobilite destekli bir rota önerisi sunulması hedeflenmektedir. Örnek alan olarak seçilen Maçka Parkı ve Gezi Parkı arasından 3 rota belirlenmiştir. Ancak rota seçiminde farklı kullanıcıların olması ya da aynı kullanıcıların farklı zamanlarda, farklı önceliklere sahip olması Analitik Hiyerarşi Süreci içindeki anket ve ikili karşılaştırma çalışmaları ile her zaman tutarlı sonuçlar vermeyebilir. Bu nedenle yöntem olarak Analitik Hiyerarşi Süreci (AHP), Bayes Ağları ile birlikte kullanılmıştır.

Çalışmada kullanıcıların rota seçimi sırasındaki amacının, o anki sağlık durumu ya da günlük programının ve psikolojik durumunun etkilerinden yola çıkılarak bazı değişkenlerin belirlenmesi ve bu modların birlikteliğine göre kriterlerin ağırlık değerlerinin değişme durumu Bayes Ağları kullanılarak çalışılmıştır.

\section{Analitik Hiyerarşi Süreci ve Bayes Ağları}

Analitik Hiyerarşi Süreci (AHP) Saaty tarafından karar verme problemleri için bir yöntem olarak geliştirilmiştir. Analitik Hiyerarşi Süreci amaç, ana ölçütler ve varsa alt ölçütler, sonrasında da karar seçeneklerinden oluşmaktadır. Bu yöntemde karar vericiler kullanılan tüm ölçütleri ve alt ölçütleri değerlendirmede 1-9 ölçeği ile hazırlanan tabloları doldurarak seçeneklerin karŞılaştırmasını yaparlar ve öncelik sıralamasında bulunurlar (Saaty, 2000).

Özetle, bu amaç doğrultusunda ana ölçütlerin belirlenmesi ve karar seçeneklerinin oluşturulması, ikili karşılaştırmaların yapılması ve sonrasında tutarlılık oranlarının belirlenmesi ile en uygun kararın verilmesi Analitik Hiyerarşi Sürecinin uygulama adımlarını oluşturmaktadır. Analitik Hiyerarşi Sürecinde 1 ile 9 arasında değerler kullanılarak, ölçütlerin kendi içinde karşılaştırıldığı matrisler oluşturulur (Şekil 1).

$$
\left[\begin{array}{cccc}
1 & a_{12} & \cdots & a_{1 n} \\
1 / a_{21} & 1 & \cdots & a_{2 n} \\
\vdots & \vdots & \cdots & \vdots \\
1 / a_{n 1} & 1 / a_{n 2} & \cdots & 1
\end{array}\right]
$$

Şekil 1. Saaty tarafından geliştirilen ikili karşılaştırma matrisi (Almeida vd., 2019). 
Karar matrisindeki ikili karşılaştırmanın sonucunun tutarlılık durumu oldukça önemlidir. Saaty tarafından tanımlanan tutarlılık oranının en üst limiti 0.10 olarak belirtilmektedir (Saaty, 2000). Analitik Hiyerarşi Sürecinde, karar verici, uzman ya da kullanıcının ikili karşılaştırma yöntemi ile kriterleri puanlaması, alternatif seçiminde karmaşık sistemleri basitleştiren bir yöntem olsa da tutarlılık oranı karar vericinin hassasiyeti ve o anki koşula bağlı kalmaktadır. Bu nedenle gündelik hayata dahil edebileceğimiz değişken karar vericiye sahip karar destek sistemlerinde Analitik Hiyerarşi Sürecini başka yöntemlerle ya da farklı ara yüzlerle desteklemek gerekmektedir.

Bayes Ağları matematiksel olarak Bayes Teoremi'ne dayanmaktadır. Bayes Teoremi olasılığa dayalı sınıflandırma yöntemidir. Bayes Teoremi'nin olasillk formülü Formül 1'de belirtilmektedir. Bayes Teoremi bir sonucun, hangi olasılıklarla, hangi kaynaktan geldiğini bulmaya yardımcı olur. Ağdaki koşullu olasılık değerlerinin çarpılmasıyla elde edilen zincir kuralı ise bir Bayes Ağı'ndaki tüm ilişkilerin nasıl oluşacağını görebileceğimiz bir kuraldır (Yücebaş, 2006). Bayes Zincir Formülü'ndeki tüm ağa ait olasılık verelerinin hesaplanması ise Formül 2'de gösterilmektedir. Bu ağlar Bayes Olasılık Kuralı ile çalışan bir karar destek sistemidir (Dereli, 2012).

$P(X 1 \mid X 2)=P(X 1) \times P(X 2 \mid X 1) / P(X 2)$

Bayes koşullu olasılık formülünde;

$\mathrm{P}(\mathrm{X} 1 \mid \mathrm{X} 2)=\mathrm{X} 2$ koşulunda $\mathrm{X} 1$ olasıllı̆̆1,

$P(X 1)=X 1$ olayının olasilığ1,

$\mathrm{P}(\mathrm{X} 2 \mid \mathrm{X} 1)=\mathrm{X} 1$ koşulunda $\mathrm{X} 2$ olasilığ

$P(X 2)=X 2$ olayının olasılı̆̆ını ifade eder.

$\mathrm{P}(\mathrm{X} 1, \mathrm{X} 2, \ldots X \mathrm{Xn})=\mathrm{P}(\mathrm{Xn} \mid \mathrm{X} 1, \ldots X \mathrm{Xn}-1) \times \mathrm{P}(\mathrm{X} 1, \ldots X \mathrm{Xn}-1)=\mathrm{P}(\mathrm{Xn} \mid \mathrm{X} 1, \ldots X \mathrm{X}-1) \times \mathrm{P}(\mathrm{X}$ $\mathrm{n}-1 \mid \mathrm{X} 1, \ldots \mathrm{Xn}-2) \times \mathrm{P}(\mathrm{X} 1, \ldots \mathrm{Xn}-2)$

Bayes Ağları ya da Bayes İnanç Ağları (Bayesian Belief Networks) değişkenleri belirten dügü̈mlerden ve değişkenler arasındaki koşullu olasılık durumlarını gösteren diyagramlardan oluşmaktadır. Dügüumler, çocuk dügümmler ve ilişkileri belirleyen oklar ve kendilerine hiç ok yönlendirilmemiş kök düğümler olarak sınıflandırılabilir. Bayes Ağları'nın yapay zekadaki olasılıksal devrimi ve akıl yürütme sistemlerinin çeşitli özelliklerinin olasılıksal çıkarımla nasıl elde edilebileceği Judea Pearl tarafından geliştirilmiştir. Pearl (1982), olasılık modellerinin kısa gösterimleri olarak ağaç yapılı ağları ve ilişkilerin düzenlenmesi için bir algoritma tanımlamıştır. Bayes Ağları genellikle 
değişkenler arasındaki ilişkilerin grafik olarak gösterilmesi ile koşullu olasılıkların belirlediği bu ilişkileri ve belirsizliklerin incelenebilmesini sağlamaktadır. Şekil 2' de, dört değişkenden oluşan örnek bir Bayes Ağı gösterilmiştir.

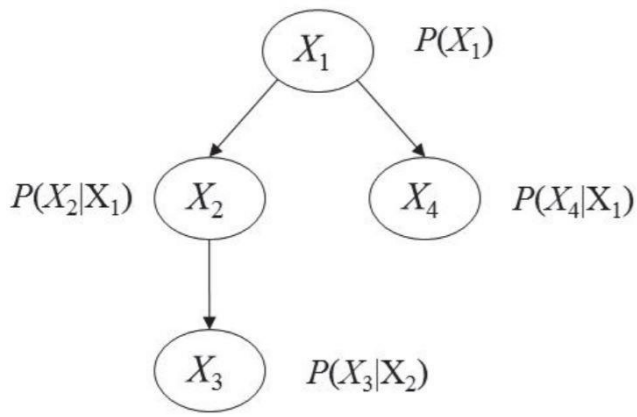

Şekil 2. Dört değişkenden oluşan Bayes Ağı gösterimi (Çinicioğlu, Önsel, Uluengin, 2015).

Bayes Ağları'nda ağ yapısı, nedensel ilişkiler dikkate alınarak ve veri setinden öğrenilerek oluşturulabilmektedir. Nedensel Bayes Ağları'nın bu noktadaki avantajı, ele alınan problemleri sadece olasılığa değil aynı zamanda nedenselliğe dayandırmasıdır (Çinicioğlu vd., 2015). İncelenen çalışmalarda, Bayes Ağları'nın, farklı kullanıcıların ürün seçimi tahmininde de kullanıldığı görülmüştür. Ji-Chun Quan and Sung-Bae Cho (2014)'nun bir çalışmasında Bayes Ağları ve Analitik Hiyerarşi Süreci kullanan çoklu kullanıcılar için akıllı bir TV programı önerme yöntemi sunulmaktadır. Önerilen yöntem, her kullanıcının tür tercihinin yanı sıra program tercihini çıkarmak için Bayes A $\breve{g}$ larını kullanır ve grup türü tercihlerini tahmin etmek ve önerilen programları seçmek için AHP'yi kullanılmıştır. Bayes Ağ modelinin doğruluğu, kullanıcıların izleme geçmişinden, makine öğrenmesi ile, parametre öğrenerek geliştirilmiştir. Predrag M. vd. (2015)'in çalışmasında ise AHP, karar vericilerin kararlarını nesneleştirmesine ve karar sürecinin resmileştirmesine izin veren bir Bayes süreci olarak düşünülmüştür. Bayes Teoremi, Stanković ve Milić (2015)'in çalışmasında aposteriori olasılıklar, yani göreceli olasılıklar elde etmek için kullanılmıştır. Şirketin faaliyetlerini ön görecek kriterlerin önemi farklı strateji olasılıkları ile birlikte değerlendirilmiştir ve AHP'deki kriterlerin öncelikleri bu stratejiler ile çakışan olasılık matrisleri yaratılmıştır. İncelenen çalışmalarda Bayes Ağları'nın hesaplanması için ve nedensel grafiklerin okunması için genellikle Netica (Norsys, 2020) ve GeNle (Bayesfusion, 2020) programları kullanılmaktadır. Ağları ve etki diyagramlarını modellemek için geliştirilen bu yazılımlar ücretli ve ücretsiz deneme sürümlerine sahiptir. Bu 
yazılımlar ile modelin oluşturulma sürecinde, temel özelliklerin programlara girilmesinden sonra her dügümün farklı kombinasyonlarının farklı olasılıktaki gerçekleşme durumları her bir düğüme ait bölüme girilmektedir. Veri girişinin ve ilişkilerin esnek bir şekilde yapılabildiği bu programlarda zor olan kısım ikiden çok ebeveyni olan düğüm örneklerinde koşullu olasılıkların uzmanlar tarafından değerlendirilmesi, anketlerin doldurulması ve hesapların sisteme girişlerinin zorluğu olarak belirtilmiştir (Dereli, 2015).

AHP'nin girdi verilerinin doğruluğunu arttırmak için Bayes formülü tarafından elde edilen olasılıkları kullanabileceği bilinmektedir (Saaty ve Vargas, 1998). Analitik Hiyerarşi Süreci, ölçütlerin göreceli önem derecelerinin belirlenmesinde, karar vericilerin sıralamalarına ihtiyaç duyulan bir yöntemdir. $\mathrm{Bu}$ yöntem ile hiyerarşik yapının oluşturulması aşamasında amaç ve amaç doğrultusunda saptanan ölçütlerin belirlenmesi ve bu ölçütlere göre en iyi alternatifin seçilmesi mümkündür. Bu nedenle kamusal alanlar arası ulaşımda mikromobilteyi destekleyecek rota seçimi bu yöntem çerçevesinde, Superdecision (Superdecision, 2020) programı kullanılarak yapılmıştır. Bayes Ağları çalışması ise GeNIe üzerinden yürütülmüştür. Bu yöntemler çerçevesinde kişiselleştirilmiş bir ulaşım modeli önerilmiştir.

\section{Kişiselleştirilmiş Ulaşım Modeli Önerisi}

Bu çalışma Analitik Hiyerarşi Süreci çerçevesinde Bayes Ağları kullanarak kullanıc tercihlerine göre bir rota seçme modeli oluşturmayı amaçlamaktadır. Bu kapsamda ilk önce karar verme sürecinde değerlendirilecek kriterler oluşturulmuştur. Bu kriterlerin ağırlık ölçütünün belirlenmesi için de Bayes Ağları kullanılmıştır. Modelin akış diyagramı şekildeki gibidir (Şekil 3). 


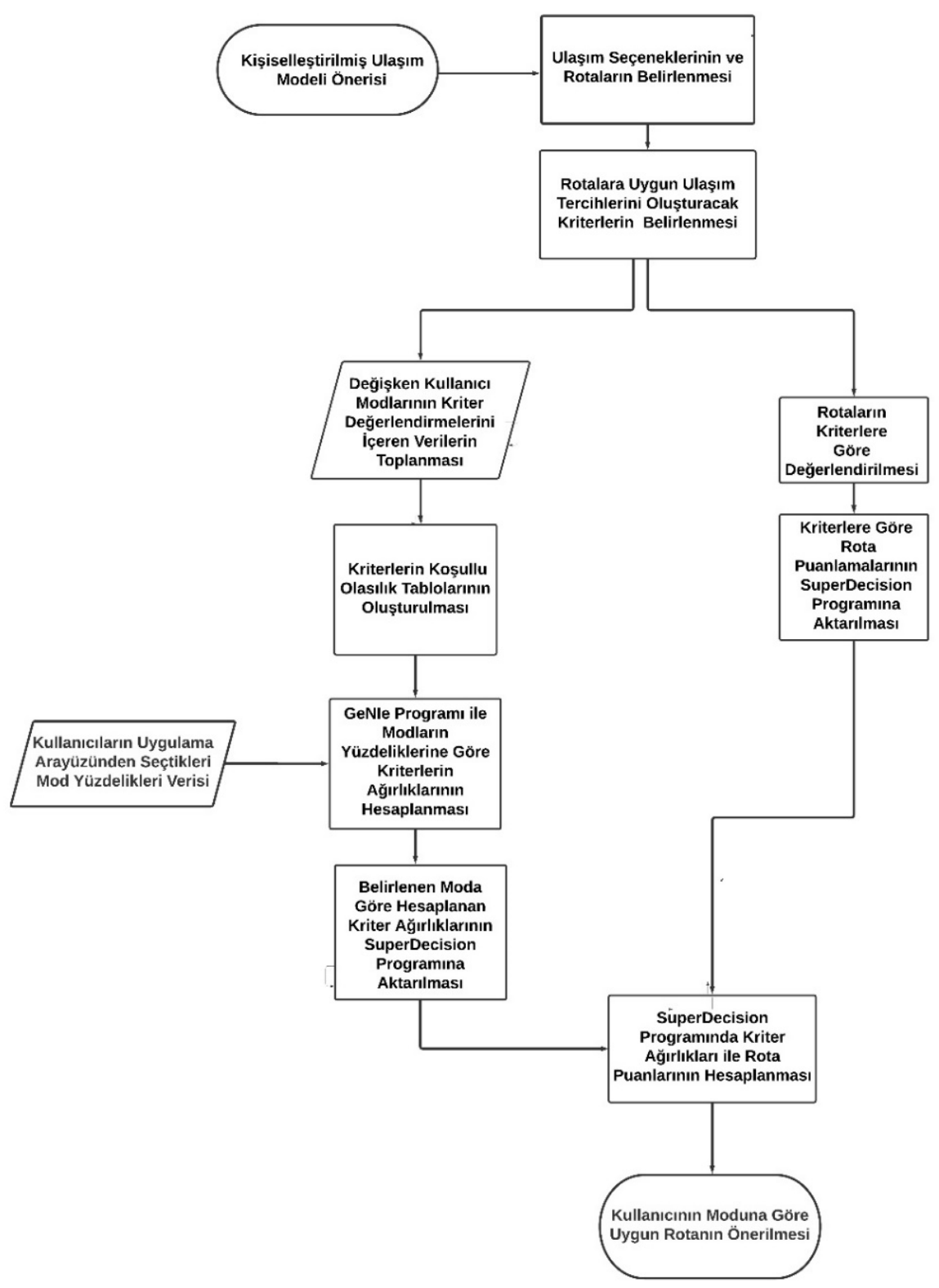

Şekil 3. Akış diyagramı 
Çalışmanın Analitik Hiyerarşi Süreci çerçevesinde, öncelikle iki kamusal alan arasında mikromobiliteyi desteklemek için e-scooter, bisiklet ve yürüme seçeneği ile bu seçeneklere uygun rotalar belirlenmiştir.

Bisiklet yolu tasarımı ve kent ölçeğinde uyulması gereken bazı kurallar olmasına rağmen tüm yollar bisiklet ve elektrikli scooter gibi saatteki hızı 10$25 \mathrm{~km} / \mathrm{sa}$ arasında olan bireysel ulaşım araçları için uygun düzenlemelere ve kentsel bir ulaşım ağına sahip olmayabilir. Bu nedenle bölgesel düzenlemeler ile kentlerde bireysel ulaşım sorunları çözülmeye çalışılmaktadır. Uygun yol koşulları ve düzenlemeler sağlansa bile kentteki her bireyin rotalardan beklentileri ve ulaşım amaçları aynı değildir. Farklı kullanıcı profilleri ya da aynı kullanıcıların farklı ulaşım amaçları rota tercihinde oldukça etkilidir. Cimler (2013)'in de çalışmalarında belirttiği gibi, farklı kullanıcı profillerinin araç ya da rota seçiminde kullanılan Analitik Hiyerarşi Süreci ile geliştirilen modellerde birçok durum kararı etkilemektedir. Sürücülerin trafikteki durumunun, sabırlı, sabırsız, tecrübeli ya da tecrübesiz gibi sınıflandırıldığı sistemlerle yapılan çalışmalar, farklı sürücü türlerinin ve kriterlerin tartışılması için zemin hazırlamıştır (Cimler, 2013). Ayrıca sosyo-ekonomik faktörler de ulaşım aracı tercihi ve rota tercihini etkilemektedir (Amine, 2018). Kullanıc1nın mesleği, yaşı, zaman ve para tasarrufu açısından özel ya da toplu ulaşım seçeneğini tercih etmesi ve bunun da mevcut rotanın trafik yoğunluğunu etkilemesi birçok çalışmada görülmüştür. Bunun dışında Dotoli vd. (2017)'nin yaptığı bir çalışmada çevre duyarlılığı, varış süresi, aktarma durumu ve araçların doluluk durumu da kriterlere eklenerek çok katmanlı ve birbiri ile etkileşimli esnek bir sistem geliştirilmiştir.

Mevcut rotalardan birinin seçimi kullanıcılar için her zaman kolay olmamaktadır, trafik yoğunluğunu gösteren uygulamalar ile bir destek sağlansa da kullanıcının o anki ruhsal durumuna, sağlık durumuna, gündelik amacına yönelik tercihler çok fazla belirgin değildir. Sunulan karar destek sistemleri genellikle en hızlı rotayı sunmak üzerine odaklanmaktadır. Bu nedenle bu çalışmada kamusal alanlar arasında bisiklet ve e-scooter gibi araçlar ile yürüyüş rotaları için uygun yollar tanımlarken farklı kullanıcı durumlarına yönelik bir rota tavsiye modeli geliştirilmesi hedeflenmiştir. Kamusal alanların kentteki farklı kullanıcıların karşılaşma noktaları olduğu düşünülerek belirli sınıflandırmalar yapılmıştır. Bu sınıflandırmalarla çeşitlenen hareketlilik kamusal alanların da sürdürülebilirliğini arttırmayı hedeflemektedir. Çok çeşitli hareketlilik seçenekleri sunmak, daha sürdürülebilir kamusal alanların yaratılmasını teşvik edebilmektedir. 
Çalışmada örnek bir model oluşturmak amacı ile sadece 3 rota sisteme dahil edilmiştir. Bu rotalar her bir ulaşım seçeneği için farklı bir alternatif olarak ayrılmıştır (Şekil 4). Çalışma için seçilen örnek alanlar; Taksim Gezi Parkı ve Maçka Parkı arasında tek yönlü rotalar BikeRoll (2020)'un uygunluk rotasına göre oluşturulmuştur (Şekil 5). Proje örnek senaryosu için seçilen 3 rota belirlendikten sonra rotaların belirlenen kriterlere göre puanlamaları yapılmıştır.

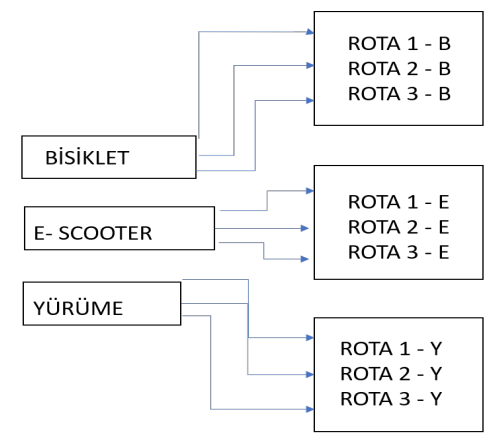

Şekil 4. Ulaşım seçenekleri içinde ikili karşılaştırılma yöntemi ile değerlendirilecek olan rotalar
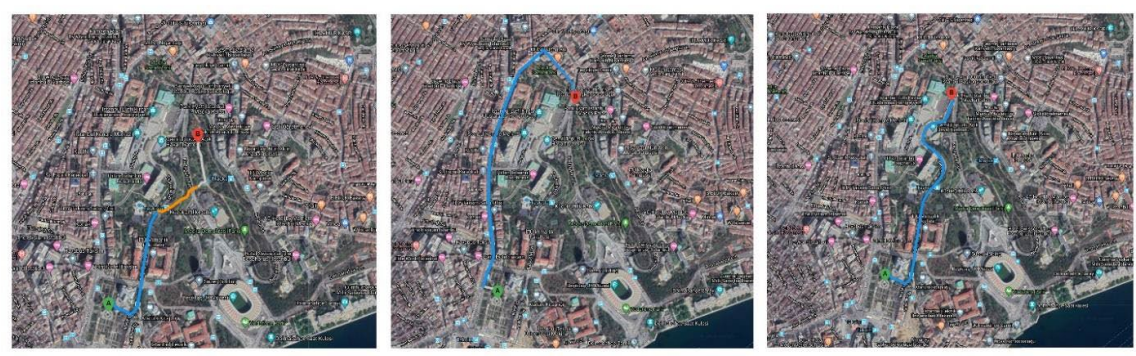

Şekil 5. Rota 1; Mete Cad., Taşkışla Cad. Maçka Parkı iç yol, Rota 2; Cumhuriyet Cad. ve Valikonağı Cad., Rota 3; Mete Cad., Taşkışla Cad.

\section{Rotalara Uygun Ulaşım Tercihlerini Oluşturacak Kriterlerin Belirlenmesi}

Seçilen iki alan arasındaki rotalardan birine karar verme sırasında gereken kriterlerin belirlenmesi için, bisiklet, e-scooter ve yürünebilirliğe yönelik literatür araştırmaları yapılmıştır. Bisiklet yolları planlanırken uyulması gereken kurallar e-scooterlar için de oldukça önemlidir. Mevcut yolların motorlu taşıt trafiği için yapılmış olması bu kriterleri ve kuralları kısıtlamaktadır. Ancak karışık trafik rotalarına, şeritle ya da banket ile ayrılarak eklenen bisiklet yolları bulunmaktadır. Bunun gibi durumlarda sağ şeridin genişliği 1.00-1.30 m arttırılarak ayrılan alan bisiklet kullanımına uygun hale getirilebilmektedir 
(Uz ve Karaşahin, 2004). İncelenen çalışmada bu yolların uygunluğunu belirleyen kriterler ise, güvenlik önceliği olan yol genişliği, tasarım hızı görüş mesafesi, eğim ve dönüş kurbu olarak belirtilmiştir. (Uz ve Karaşahin, 2004).

Bölgesel Güvenli Bisiklet Yolları Projesinde ise güzergâh seçimi aşamasında, ilgili kentin topoğrafyasına, kullanıcı eğilimlerine, güzergâh uzunluğuna, sokak genişliklerine, nüfus dağılımına, ana kentsel kullanımlara dikkat edilmiş ve bu kriterlere göre rotalar belirlenmiştir (Öztaş, vd. 2016). Bu çalışmalar dikkate alındığında, rotaların eğimi ve genişliği güvenliği, uzunluğu ise yol durumunu belirleyen önemli kriterlerdir. Kullanıcının eğilimleri ve nüfus durumu ise rotaların bulunduğu çevresel etkilerle ilişkili olarak değerlendirilmiştir. Önerilen modelde mevcut yollar üzerinden değerlendirme yapılacağı için, eğim, genişlik uzunluk kriterleri belirlenmiştir. Sürenin farklı kullanıcı tercihleri için önemli olacağı düşünülerek kriterlere eklenmesi ise yoğunluğun da kriterlere dahil olmasına neden olmuştur.

Kamusal alanlar ve kentsel hareketlilik arasındaki ilişkinin dengelenmesi için yapılan bazı araştırmalarda, kamusal alanlar arasındaki ulaşım ağlarının daha cazip hale getirilmesi için çalışmalar yapılmıştır. Ravazolli ve Torricelli (2017)'nin makalesinde kamusal alanların sürdürülebilirliği, kentsel hareketlilik çerçevesinde incelenmiş ve Danimarka'nın başkenti Kopenhag, yürüyüş ve bisiklete binmenin yaygın olduğu yerlerde bir kamusal alan ağının nasıl daha sürdürülebilir olacağı örnek olarak verilmiştir. Ayrıca bu makalede sürdürülebilir hareketlilik tanımı, toplumun özgürce hareket etme, erişim elde etme, iletişim kurma ihtiyaçlarını ekolojiden ve insani gerekliliklerden ödün vermeden sağlaması olarak belirtilmiştir (Ravazolli ve Torricelli, 2017). Bu noktada kamusal alanların ve çevresindeki ağın devamlılı̆̆ için rotaların yaşayan mekanlar olması ve yeşil alanlarla ilişkisi önem kazanmaktadır. Bu nedenle çalışmada rotaların belirlenmesinde çevresel etki kriterleri yeşil alanların ve çevre mekanların canlılığı kapsamında değerlendirilmesine karar verilmiştir. Yapılan araştırmalar sonucu belirlenen bu kriterler aynı zamanda Bayes Ağları'nda değişken kullanıcıların değerlendirdiği kriterlerdir.

Bu çalışma kapsamında uygulanacak modelde;

- Güvenlik kapsamında ele alınacak kriterler:

- Yol Eğimi: Araç yolunun ya da varsa seçilen ulaşım tercihi için ayrılmış özel yolun eğimi,

- Yol genişliği: Araç yolunun ya da varsa seçilen ulaşım tercihi için ayrılmiş özel yolun genişliği;

- Rotalara yönelik kişisel tercihler için oldukça önemli olan kriterler:

- Süre: Uzaklık ve hız değerlerine göre değişen süre, 
- Yoğunluk: Trafik yoğunluğu;

- Kamusal alanların kentsel hareketlilikle olan çift yönlü ilişkisini belirleyen kriterler:

- Kentsel tasarım, park ve yeşil alan durumu;

- Çevre koşulları, mekânsal canlılık.

\section{Değişken Kullanıcı Modlarının Belirlenmesi}

Akış diyagramında da görülüğü gibi çalışma Bayes Ağları ve Analitik Hiyerarşi Süreci iki ayrı koldan sürdürmektedir. Bayes Ağları bölümünde öncelikle kullanıcıların rota tercih sistemini en kolay ve etkin kullanabilmesi düşünülmüştür. Bayes Ağları ile kullanıcıların kendi modlarını belirli yüzdeler ile farklı kombinasyonlar oluşturarak verdiklerinde bu yüzdelerin kriterlerin önemini nasıl belirleyeceği hesaplanabilmektedir. Bu önem değerlerinin oluşturulmasından önce farklı kullanıcı modlarının kriterlere vereceği önem değerlerinin belirlenmesi için uzman görüşüne bağlı Nedensel Bayes Ağları seçilmiştir. Nedensel Bayes Ağı oluşturulurken ve modelde kullanılan değişkenler (değişken kullanıcı modları) belirlenirken, kamusal alanların kullanıcılarına öncelik verilmiştir. Rota seçiminde sağlık ve yaş durumları da önemli olacağı için gezgin (sağlıklı, genç), sportif (aktif, spor amaçlı gezmeyi hedefleyen ya da genç ve sağlıklı), maceracı (gezgin, genç ve korkusuz), aceleci (buluşma noktasına yetişmeye çalışan) olarak, kullanıcılar dört değişken mod sınıfına ayrılmıştır. Bu dört değişkenden oluşan kullanıcı sınıfları, modeli oluşturmak amacıyla seçilmiştir. Değişken kullanıcı modlarının sayıları arttıkça modelin esnekliği artacaktır. Tabloda kriterlerin düğüm olarak tanımlandığı değişken kullanıcı modlarının ise ebeveyn olduğu Nedensel Bayes Ağı oluşturulmuştur (Şekil 6).

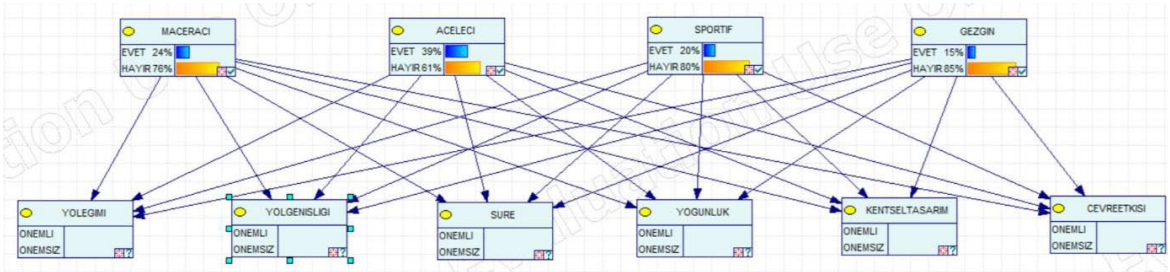

Şekil 6. Kriterlerin düğüm olarak tanımlandığı değişken, kullanıcı modlarının ise ebeveyn olduğu Nedensel Bayes A $\breve{g}$ 


\section{Değişken Kullanıcı Modlarının Kriter Değerlendirmelerini İçeren Veri Setlerinin Oluşturulması}

Belirlenen kriterlerin, kullanıcı tercihlerine göre farklı olasılıklardaki bir aradalık durumunu değerlendirebilmek için web üzerinden bir anket oluşturulmuştur (Şekil 7). Bu ankette kullanıcılara farklı modlarda olduklarında hangi kriterleri önemseyecekleri sorulmuş daha sonra elde edilen veriler birleştirilerek koşullu olasılık tablolarına aktarılmıştır. Çevirimiçi yapılan ankette, 20 ile 65 yaşları arasındaki 51 kişiden analizlerde kullanılabilecek veriler elde edilmiştir. Anket çalışmasında oluşturulan matriste kullanıcıya maceracı olma durumda önemli olduğunu düşündüğü kriterler, aceleci olma durumda önemli olduğunu düşündüğü kriterler, sportif hissettiğinde önemli olduğunu düşündüğü kriterler ve gezgin olduğu zamanlarda önemli bulduğu kriterler sorularak model için eğitici veri seti oluşturulmuştur. Bu anket sonucu her kişinin verileri, farklı modların aynı anda bulunma koşulları üzerinden tek tek değerlendirilerek koşullu olasılıklar tablosuna eklenmiştir.

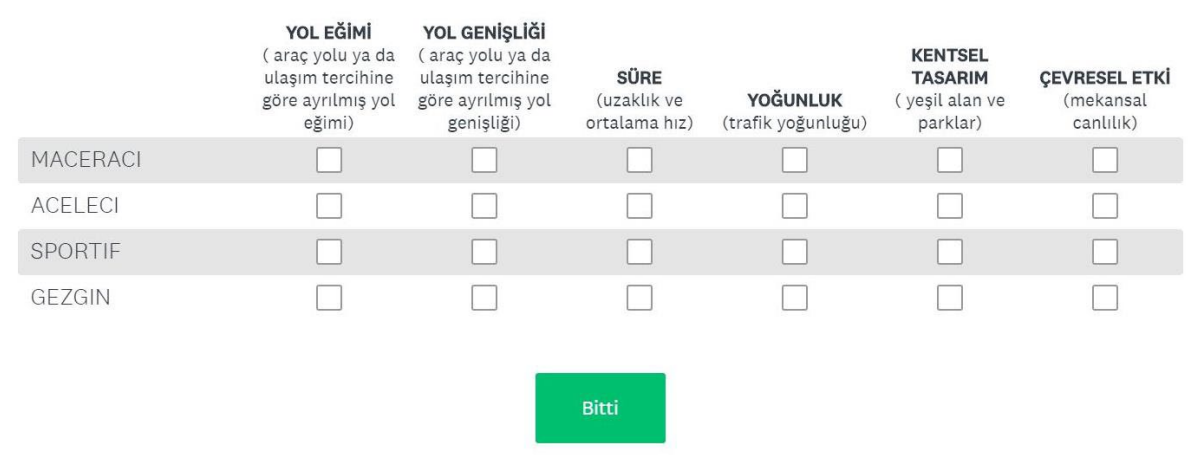

Şekil 7. Nedensel Bayes Ağı değişken modu ve kriterler anketi (https://tr.surveymonkey.com/r/C23G6L7)

\section{Kriterlerin Koşullu Olasılıklarının Hesaplanması}

Koşullu olasılık tablolarının oluşturulması için yapılan anket sonuçlarına göre, kişilerin farklı modlarda önemli buldukları kriterler tabloya girilmiştir. Bu tabloları açıklamak gerekirse, Şekil 9'da görülen yol eğimi koşullu olasılık tablosunda, maceracı olma durumunda yol eğimini önemli bulan kullanıcı sayısı toplamda 30, bulmayan kullanıcı sayısı ise 21'dir. Maceracı olma durumunda, aceleci olma durumunda, sportif ve gezgin olma durumlarında yol eğimini önemli bulanların sayısı 4, bunların hepsinde aynı anda önemli bulmayanların sayısı 26'dır. Bu durumda koşullu olasılık yüzdesi, 0,13 olarak 
hesaplanmıştır. Şekil 9'daki tabloda da görüldügü̈ gibi maceracl, aceleci, sportif olma durumunda yol eğimini önemseyen ancak gezgin olma durumunda bu kriteri önemsemeyenlerin sayısı ise 5 'tir. Bu durumun olasılık yüzdesi ise 0,17 olarak hesaplanmıştır. Maceracı, aceleci, gezgin olduğu modlarda yol eğimini önemli olduğunu düşünen kişi sayısı 5, koşullu olasılık yüzdesi 0,17 , maceracı ve aceleci olduğunda yol eğimini önemseyen ama sportif ve gezgin olduğunda önemsemeyen kişi sayısı 11 'dir; bu olasılı̆̆ın değeri ise 0,37 olarak hesaplanmıştır. Maceracı ve sportif olduğunda yol öneminin önemli olduğunu düşünen ancak gezgin ve aceleci olduğunda önemsiz olduğu düşünen kişi sayısı 7, koşullu olasılık tablosundaki değeri ise 0,23 olarak hesaplanmıştır. Maceracı ve sportif olduğu durumlarda yol eğimini önemseyen kişi sayısı 15'tir ve olasılık değer 0,5'tir. Maceracı ve gezgin olduğu durumda yol eğimi kriterini önemseyen ise 9 kişidir burada ise koşullu olasılık 0,3'tür. Sadece maceracı olduğu durumda yol eğimini önemseyen kişi sayısı ise 9 kişi olup buradaki koşullu olasılık durumu 0,3'tür. Bu tablonun diğer kısmında ise yine ayn yöntemle maceracının yol eğimini beğenmediği durumlardaki farklı kombinasyonlar, anket sonucundaki verilere göre hesaplanmıştır. Bu tablo ve diğer kriterlerin tabloları ise aşağıda verilmiştir (Şekil 8), (Şekil 9), (Şekil 10), (Şekil 11), (Şekil 12) ve (Şekil 13). Bu tablolar daha sonra GeNIe programı üzerinden oluşturulan Nedensel Bayes Ağı ortamındaki düğümlere (nodlara) aktarılmıştır. Anket çalışması sonucu 51 değerlendirme, 6 kriterin koşullu olasılık tablosuna işlenmiştir.

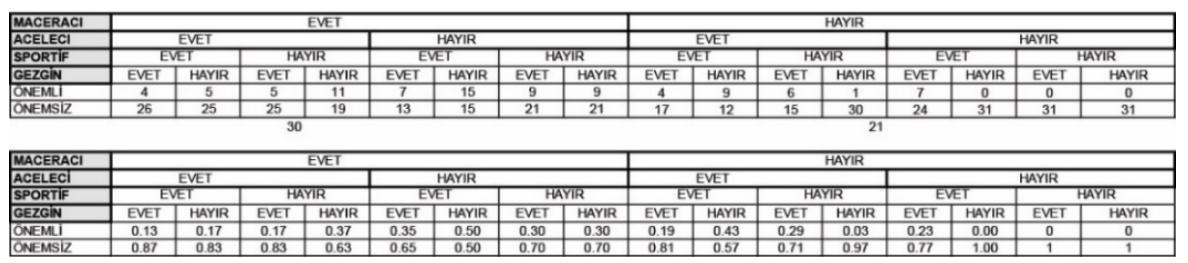

Şekil 8. Yol Eğimi Koşullu Olasılık Tablosu

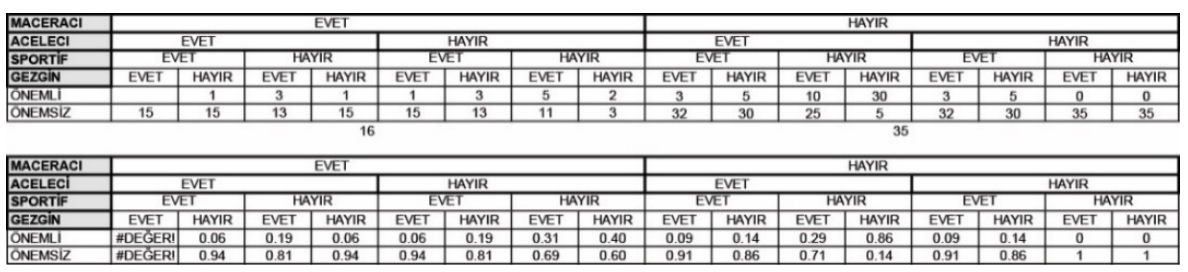

Şekil 9. Yoğunluk Olasılık Tablosu 

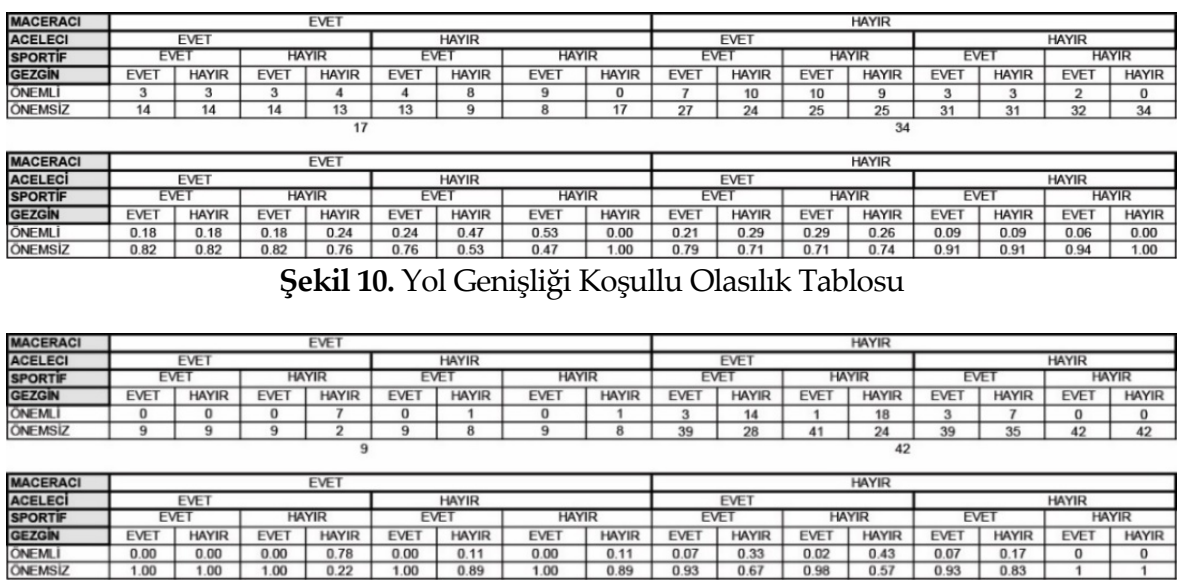

Şekil 11. Süre Koşullu Olasılık Tablosu

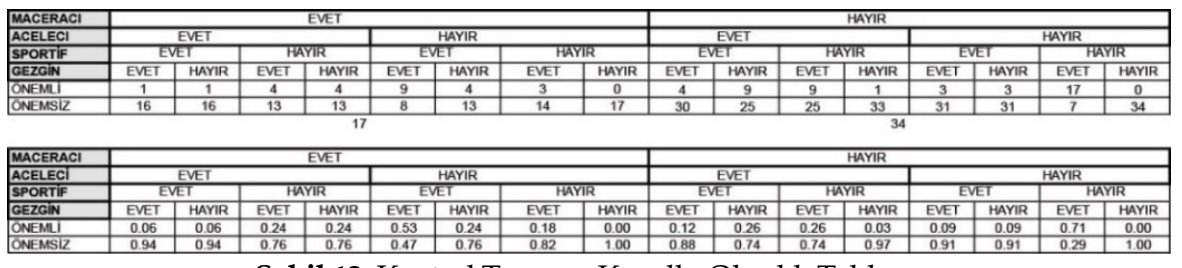

Şekil 12. Kentsel Tasarım Koşullu Olasılık Tablosu

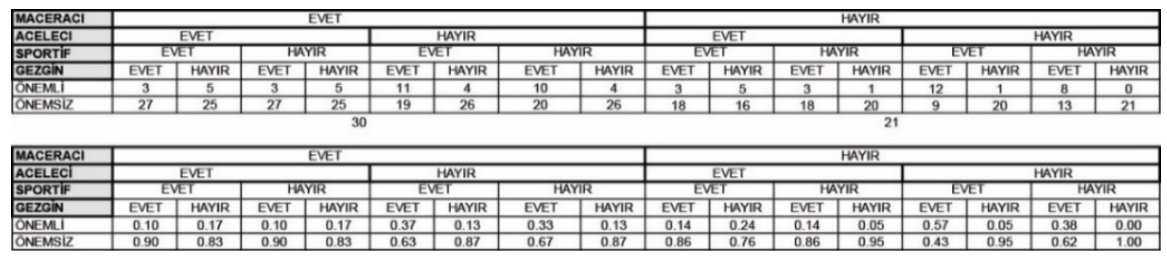

Şekil 13. Çevre Etkisi Koşullu Olasılık Tablosu

\section{Kullanıcının Değişken Modlarını Belirlemesi}

Bu çalışmada Bayes Ağında değişken olarak belirlenen farklı kullanıcı modları dört sınıfa ayrılmıştır. Ayrılan dört sınıfın Bayes Ağlarındaki koşullu olasılık hesapları sonucu çıkan yüzdelik değerleri daha sonra AHP kullanıcı profilleri olarak dahil edilmiştir. Bu veri seti, Makine Öğrenmesi çalışmalarında Bayes Ağ1 ile geliştirilen tavsiye sistemlerinde kullanılan, Eğitici Veri Seti (Training Data) olarak düzenlenmiş, algoritmalara girecek hazırladığınız veridir. Veri seti sisteme girildikten sonra kullanıcıların kendi modlarının yüzdeliklerine göre tüm düğ̈̈mlerin olasılıkları hesaplanarak, kullanıcıların değişken modlarda kriterlere verdikleri önem değerlerine göre bir rota seçimi- 
nin sağlanması hedeflenmiştir. Kullanıcılar bir uygulama arayüzü ile değişken modlarını belirleyebilirler ya da her kullanıc kendi için sabit bir mod kaydedebilir (Şekil 14). Bayes Ağları'nda, kullanıc modu değişkenlerinin yüzdesinin değişimi ile her kritere farklı ağırlık yüzdesi hesaplanmaktadır ve bu yöntemin karar destek sistemini daha esnek hale getirdiği düşünülmektedir.

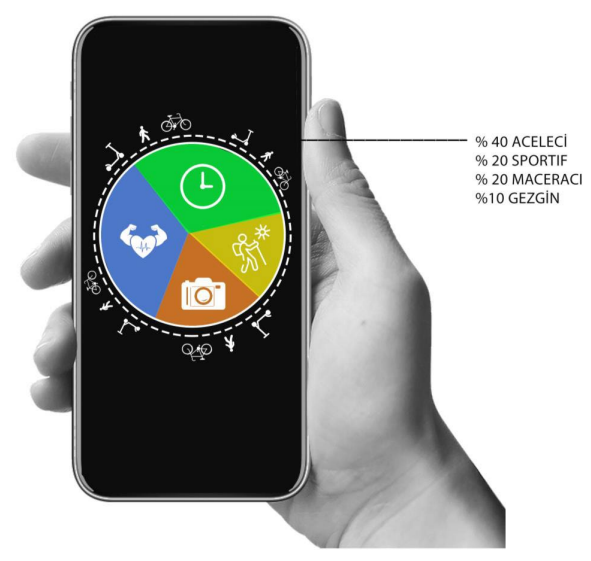

Şekil 14. Kullanıcıların değişken modlarını belirleyebileceği arayüz tasarımı

\section{Rotaların Kriterlere Göre Değerlendirilmesi}

Çalışmada Bayes Ağları ile kriterlerin ağırlıklarının belirlenmesine ek olarak Analitik Hiyerarşi Süreci ile bir rota seçimi yapılabilmesi için, rotaların da ağılık değerlerinin belirlenmesi gerekmektedir. Rota seçimini yapabilmek ve rotaların kriterlere uygunluk durumunu puanlayabilmek amacıyla öncelikle bazı temel varsayımlarda bulunulmuştur.

İlk aşamada;

- Mevcut rotada bulunan trafik akışı hızı eş zamanlı olarak çalışmaya dahil edilmemiştir.

- Bisiklet, e-scooter ve yürüme hızı sabit referans değerlerde alınmıştır. Bu değerler bisiklet için $25 \mathrm{~km} / \mathrm{s}$, e- scooter için $18 \mathrm{~km} / \mathrm{s}$, yürüme için $5 \mathrm{~km} / \mathrm{s}$ olarak kabul edilmiştir.

- Bisiklet ve e-scooterın parklardaki tedarik süresi ve paylaşım sistemi modele dahil edilmemiştir.

- Maçka Parkı'nın sınırlarından, Gezi Parkı'nın ortasındaki havuzlu meydan arasında, karar destek sisteminde kullanılmak üzere 3 rota, eğim ve uygunluk durumuna göre Bikeroll'un hazırladığı haritalar aracılığı ile seçilmiştir. 
Kriterlerden, güvenliği belirleyici olan yol eğimi ve yol genişliğinin uygunluğu BikeRoll'un oluşturduğu rotalar üzerinden, yol durumuna ait veriler ise İstanbul Büyükşehir Belediyesi Ulaşım Daire Başkanlığı verilerine göre sisteme girilmiştir (Şekil 15). Kentsel tasarım kriterini oluşturan, tasarlanmış yeşil alanlar ve yolların tasarım durumu, İBB'nin parklar haritasından elde edilmiştir (Şekil 16). Çevresel etki kriteri ise rota üzerindeki twitter verilerinin yoğunluğunu lokasyon bilgisi üzerinden tespit edebildiğimiz Grasshoppher Mosquito eklentisi ile yoğunluk akslarının karşılaştırılmasına göre belirlenmiştir (Food4rhino, 2020). Çevresel etki kriterinin anlık verilerle değişebilmesi ve çevrenin yoğunluğunu eş zamanlı ölçebilmek, fiziksel kamusal alan ile sanal kamusal alan verilerini çakıştırmak adına önemlidir. Bu çalışmada rotaların bulunduğu ana cadde isimleri adres bölümüne girilerek o rotalardaki tweet sayısı 100 ile sınırlandırılarak hesaplanmıştır. Veriler, güncel olmasi için 29.05.2020 de en popüler olan tweet'den girilmiştir. Buna göre rota1 deki tweet say1s1 80, rota 2'deki tweet say1s1 48 ve rota 3'te bulunan tweet sayısı 52 olarak görülmektedir (Şekil 17), (Şekil 18) ve (Şekil 19). Çevresel etki puanı bu verilere göre tabloya girilmiştir. Çevresel etki verilerinin anlık değişkenliğinden dolayı kullanıcıların gündelik değişken modları ile uyum sağlayacağı için seçilen bu yöntem sonucu değerlendirme sayılar arası kıyaslamaya göre puanlanmıştır. 


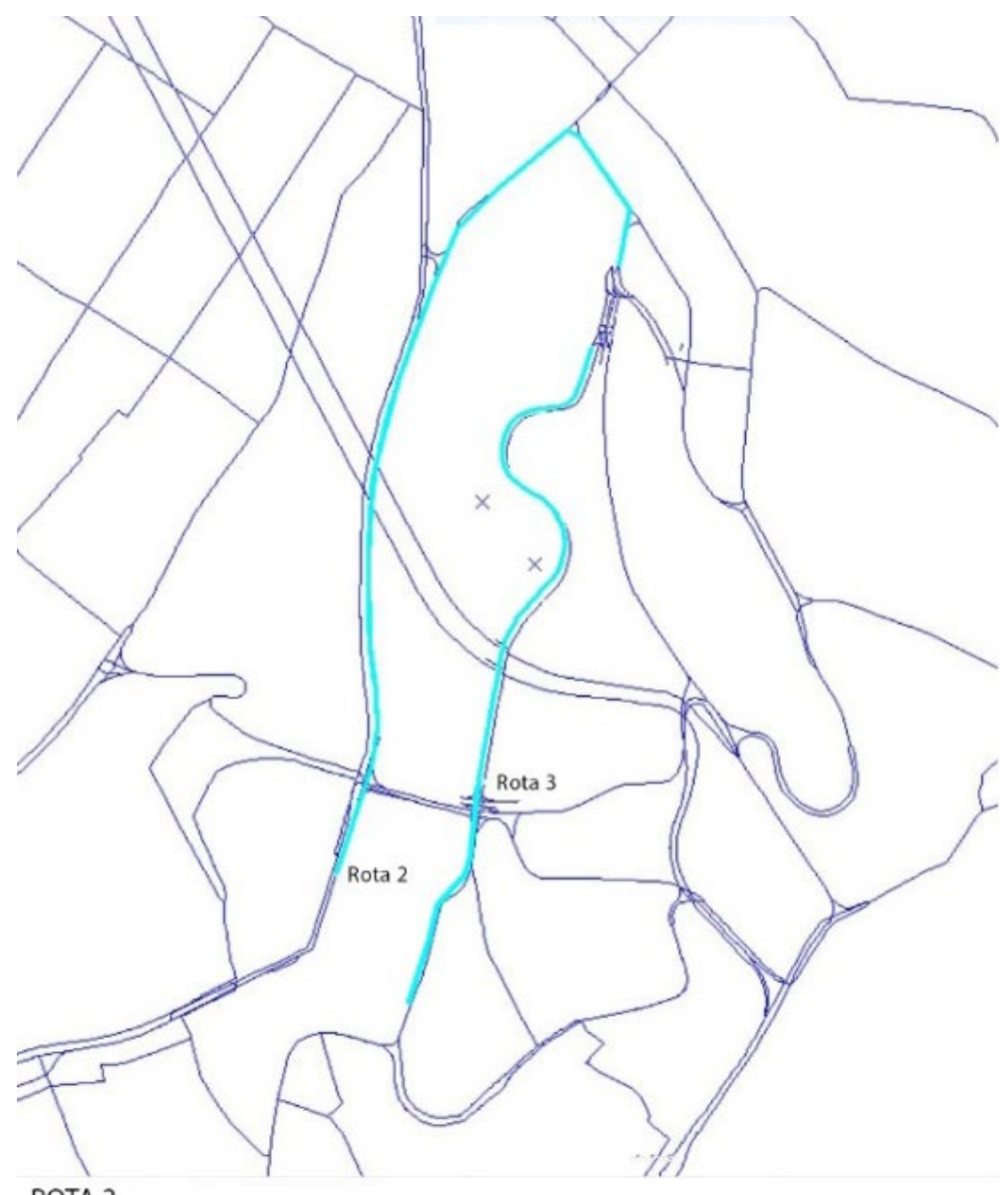

ROTA 2

\begin{tabular}{r|r|r|r|}
\hline AB KAP 7 9 & BA KAP 7 9 & AB PRE 7 9 & BA PRE 7 9 \\
\hline 1792 & 1792 & 32 & 0
\end{tabular}

ROTA 3

\section{\begin{tabular}{r|r|r|rr}
\hline AB KAP 7 9 & BA KAP 7 9 & AB PRE 7 9 & BA PRE 7 9 \\
\hline 5376 & 0 & 622.463565 & 0
\end{tabular}}

Şekil 15. Rota 3 - Çift yön Araç kapasitesi sa. 1792 araç; Rota 2- Tek yön araç kapasitesi sa. 5376 araç; Rota 1- Mete Caddesi devamında park içine dahil olduğu için az yoğun olarak puanlanmıştır. 


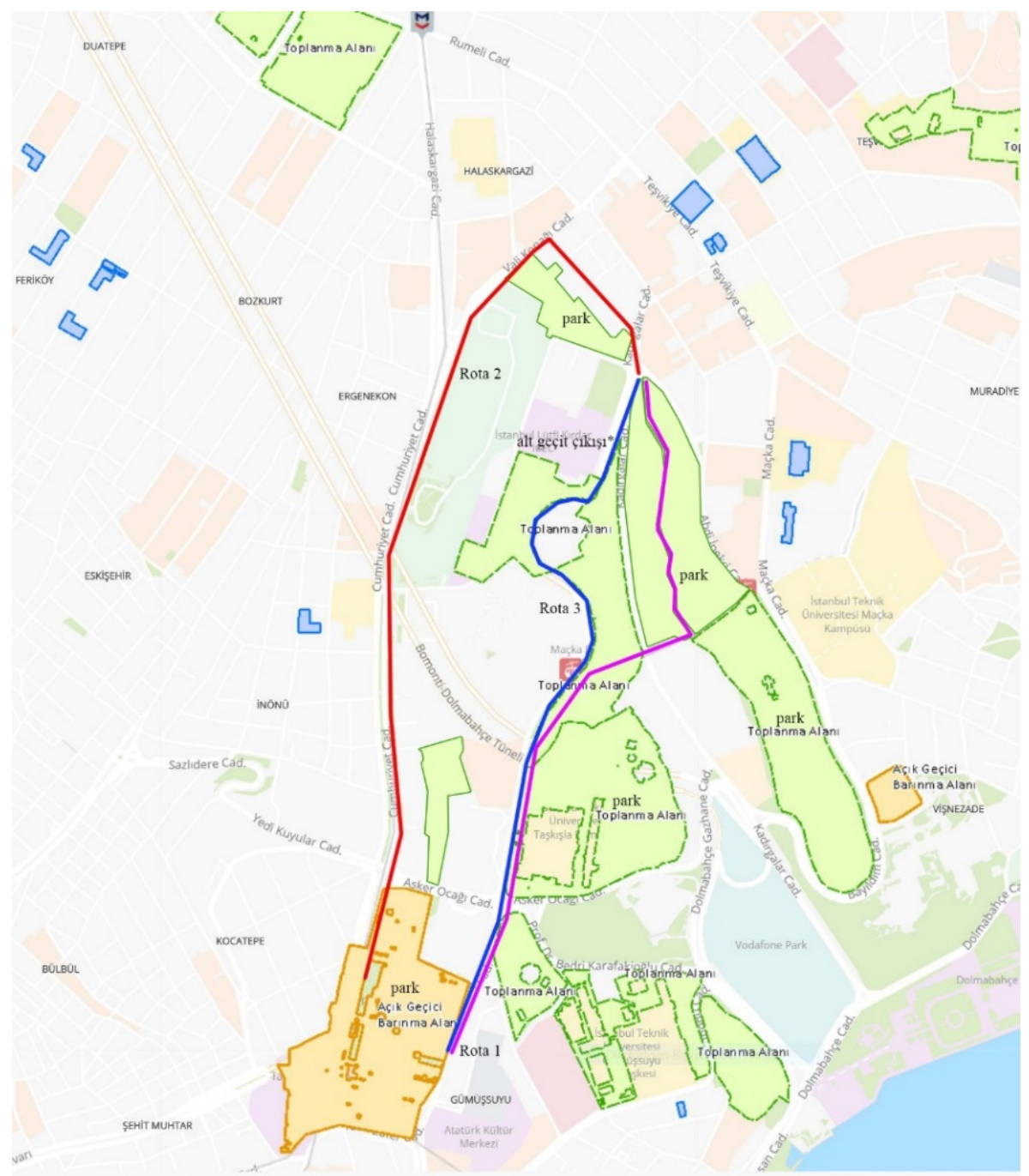

- Rota 1 park, bisiklet için düzenlenmemiș

- Rota 2 düzenlenmiş, daralan araç yolu

- Rota 3 düzenlenmiş geniș kaldırım ve araç yolu

Şekil 16. İBB park ve toplanma alanları haritası üzerinde rotaların durumu. 


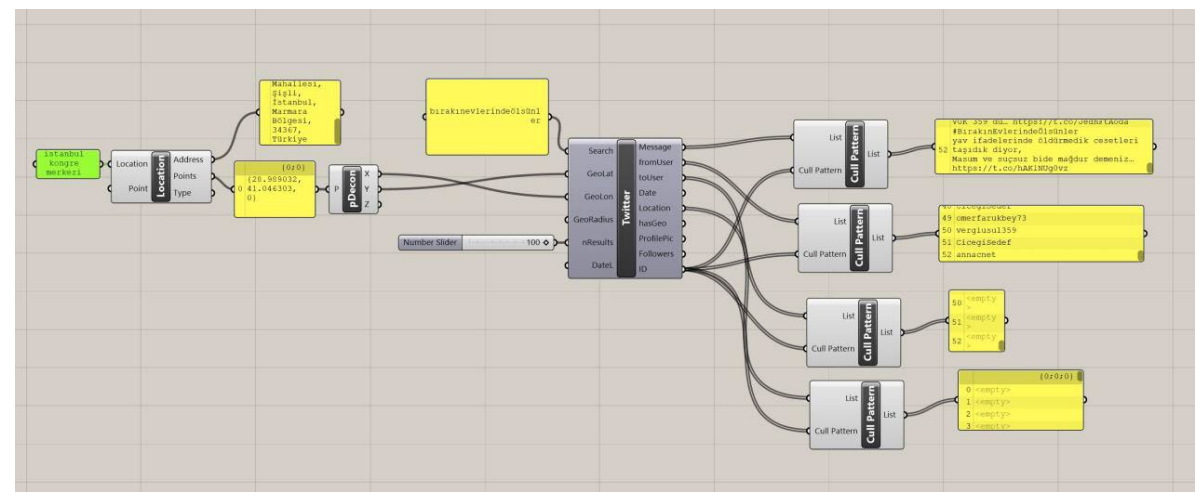

Şekil 17. Rota 1 Taşkışla Caddesi - Maçka Parkı iç yol

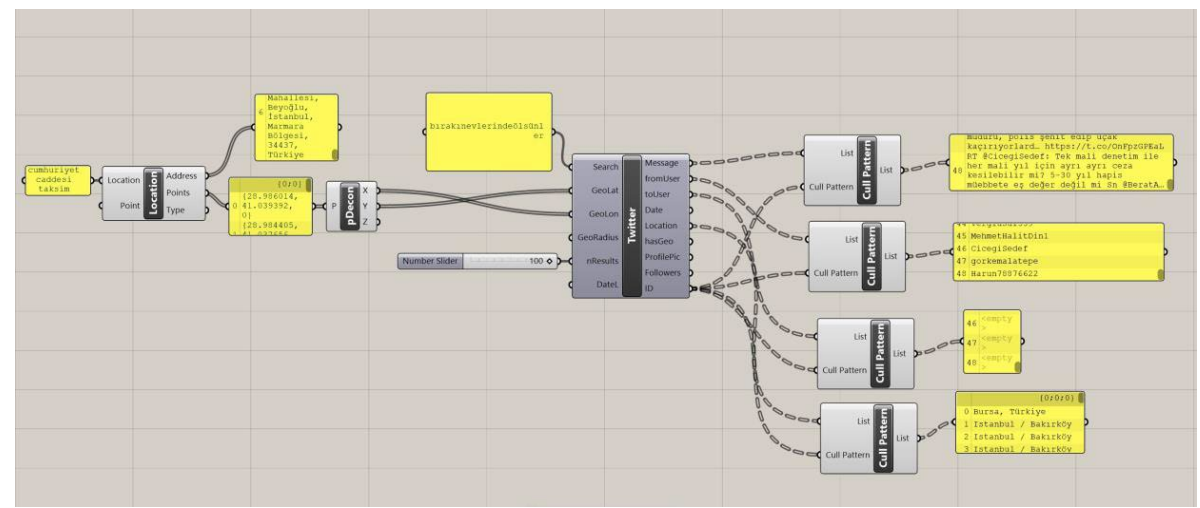

Şekil 18. Rota 2 Cumhuriyet Caddesi

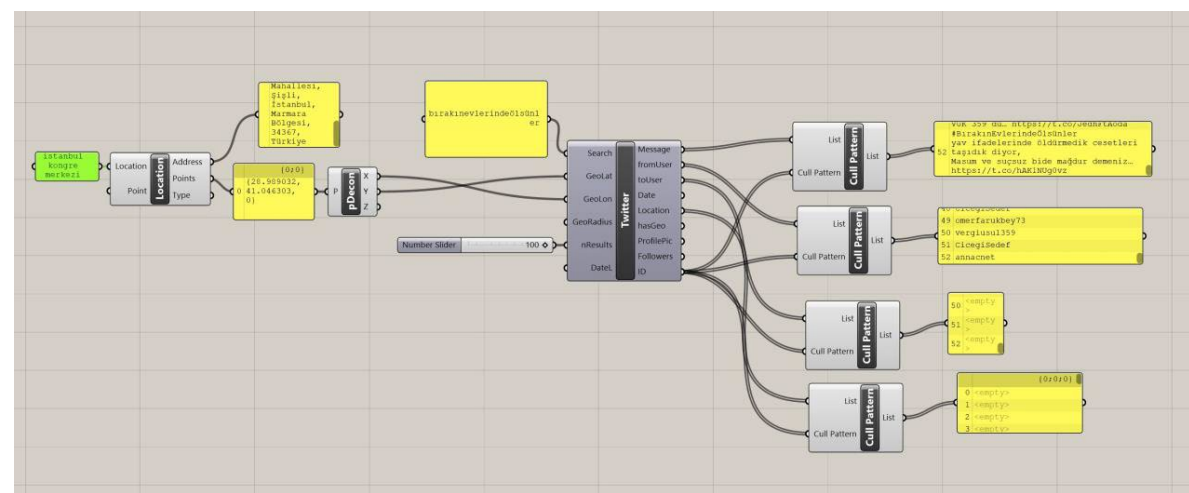

Şekil 19. Rota 3 İstanbul Kongre Merkezi yolu 
Bu veriler doğrultusunda rotaların özelliklerine göre kriterlerin puanlanabilmesi için her bir ulaşım seçeneğine göre bazı alt ölçütler belirlenmiştir. Bisiklet ve e-scooter rotaları için eğim durumunun alt ölçütlere göre belirlenen puan tabloları, literatür araştırmalarındaki, araç yolu ve bisiklet yolunun birlikte olduğu ideal çözümlere göre alt ölçütler belirlenmiştir. Bu tablolara göre genişliğin $12 \mathrm{~m}$ olduğu durumlar araç ve bisiklet için bisiklet yolu ayrımı ile birlikte bisiklet ve e-scooter kullanımı için dönüştürülmeye uygundur. Tabloda verilen kısaltmalarda YY olarak verilen Yaya Yolu değerleri ve BY olarak verilen Bisiklet Yolu değerleri literatür çalışmalarından alınan minimum değerlere göre düzenlenmiştir. Tercih edilen değer dışında uyarlanabilir bisiklet yolu ve e-scooter yolları için $9 \mathrm{~m}$ araç yolu ve 1,2 $\mathrm{m}$ bisiklet yolu genişliği olan yollar 7; $6 \mathrm{~m}$ araç yolu ve 2,4 m bisiklet yolu genişliği olan yollar 5; 4,5 m araç yolu ve 2,2 m Yaya Yolu genişliği olan yollar üç ve sadece tek araç geçişine izin verilen yollar ise bisiklet ve e-scooter için 1 puan olarak kabul edilmiştir. Bu ölçütlere göre 1-9 arası puanlama ile ulaşım seçeneklerinin rota seçiminde tutarlılık sağlanması amaçlanmıştır (Şekil 20). Bu ölçütlerin puanlama sisteminde her ulaşım seçeneğine göre rotaya uygunluk durumu puana göre belirlenmiştir (Şekil 21). Bu puanlar alternatiflerin içinde her bir rotanın değeri olarak, belirleyici kriterler için "direct " bölümünden girilmiştir (Şekil 22).

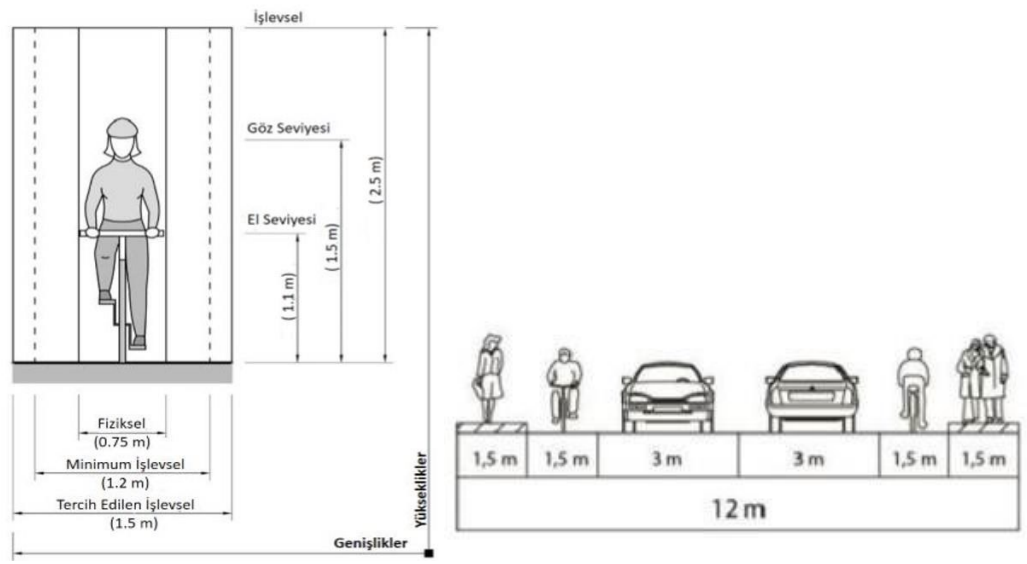

Şekil 20. Bisiklet yolu ve araç yolu ilişkisi Küçükpehlivan ve Doğru (2015) 
BISIKLET hız $25 \mathrm{~km} / \mathrm{sa}$

\begin{tabular}{|c|l|c|c|l|l|c|}
\cline { 2 - 7 } \multicolumn{1}{c|}{} & eğim & genişlik & SÜRE / dk & YOĞUNLUK & kentsel tasarım & çevresel etki \\
\hline 1 & $\% 10+$ & 3.5 & $15+$ & çOK YOĞUN & düzenlenmemiş & $0-10$ T. kullanıcı \\
\hline 3 & $\% 9-\% 10$ & $4.5 /$ YY 2 & 15 & BíRAZ YOĞUN & hızlı araç yolu & $10-30$ T. kullanıcı \\
\hline 5 & $\% 6-\% 8$ & $6 /$ YY 2.4 & 10 & YOĞUN & düzenlenmiş araç yolu ve y & $30-50$ T. kullanıcı \\
\hline 7 & $5 \%$ & $9 /$ BY 1.2 & 4 & AZ YOĞUN & yaya yolu - araca kapalı yol & $50-100$ T. kullanıcı \\
\hline 9 & $<\% 2$ & $12 /$ BY 2.4 & 3 & YOĞUN DEĞiL & park ve düzenlenmiş & $100+$ T. kullanıcı \\
\hline
\end{tabular}

\begin{tabular}{|c|c|c|c|c|c|c|}
\hline ROTA 1 & $12 \%$ & $5+Y Y 2$ & 2.4 & YOĞUN DEĞiL & düzenlenmemiş & 80 \\
\hline & 1 & 3,5 & 6 & 3 & 1 & 9 \\
\hline ROTA 2 & $6 \%$ & 8 & 4 & YOĞUN & düzenlemiş, araç yolu & 48 \\
\hline & 5 & 6 & 7 & 5 & 5 & 5 \\
\hline ROTA 3 & $6 \%$ & $6+Y Y 2$ & 3.6 & AZ YOĞUN & düzenlemiș, araç yolu & 52 \\
\hline
\end{tabular}

\section{E-SCOOTER hız $18 \mathrm{~km} / \mathrm{sa}$}

\begin{tabular}{|c|l|c|c|l|l|c|}
\cline { 2 - 7 } \multicolumn{1}{c|}{} & eğim & genişlik & SÜRE / dk & YOĞUNLUK & kentsel tasarım & çevresel etki \\
\hline 1 & $\% 10+$ & 3.5 & $15+$ & ÇOK YOĞUN & düzenlenmemiş & $0-10$ T. kullanıcı \\
\hline 3 & $\% 9-\% 10$ & $4.5 /$ YY 2 & 15 & BiRAZ YOĞUN & hızlı araç yolu & $10-30$ T. kullanıcı \\
\hline 5 & $\% 6-\% 8$ & $6 /$ YY 2.4 & 10 & YOĞUN & düzenlenmiş araç yolu ve & $30-50$ T. kullanıcı \\
\hline 7 & $5 \%$ & $9 /$ BY 1.2 & 4 & AZ YOĞUN & yaya yolu - araca kapalı y & $50-100$ T. kullanıcı \\
\hline 9 & $<\% 2$ & $12 /$ BY 2.4 & 3 & YOĞUN DEĞiL & park ve düzenlenmiş & $100+$ T. kullanıcı \\
\hline
\end{tabular}

\begin{tabular}{|c|c|c|c|c|c|c|}
\hline ROTA 1 & $12 \%$ & $5+Y Y 2$ & 4 & YOĞUN DEĞiL & park ve düzenlenmiş & 80 \\
\hline & 1 & 3,5 & 7 & 3 & 9 & 9 \\
\hline ROTA 2 & $6 \%$ & 8 & 5 & YOĞUN & düzenlenmiş araç yolu & 48 \\
\hline & 9 & 9 & 6 & 5 & 5 & 5 \\
\hline ROTA 3 & $6 \%$ & $6+Y Y 2$ & 5.6 & AZ YOĞUN & düzenlenmemiş & 52 \\
\hline
\end{tabular}

YÜRÜME hız $5 \mathrm{~km} / \mathrm{sa}$

\begin{tabular}{|c|c|c|c|c|c|c|}
\hline & eğim & genişlik & SÜRE / dk & YOǦUNLUK & kentsel tasarım & çevresel etki \\
\hline 1 & $\% 10-\% 20$ & vaya yolu yok & $30+$ & ÇOK YOĞUN & düzenlenmemiş & 0-10 T. kullanıcı \\
\hline 3 & \%9-\%10 & $8+Y Y_{2}$ & 20 & BİRAZ YOĞUN & hızlı araç yolu & 10-30 T. kullanıcı \\
\hline 5 & $\% 10-\% 7$ & $7+Y Y 2$ & 15 & YOĞUN & düzenlenmiş araç yolu + & 30-50 T. kullanıcı \\
\hline 7 & \%5-8 eğim & $6+Y Y 2$ & 10 & AZ YOĞUN & yaya yolu - araca kapalı y & 50-100 T. kullanıc \\
\hline 9 & $<\% 2$ & $4+Y Y 2$ & 5 & YOĞUN DEĞiL & park ve düzenlenmiş & $100+T$. kullanıcı \\
\hline
\end{tabular}

\begin{tabular}{|c|c|c|c|c|c|c|}
\hline ROTA 1 & $12 \%$ & $5+Y Y 2$ & 14 & YOĞUN DEĞiL & park ve düzenlenmiş & 80 \\
\hline & 1 & 8 & 8 & 3 & 9 & 9 \\
\hline ROTA 2 & $6 \%$ & $8+Y Y 2$ & 18 & YOĞUN & düzenlemiş, araç yolu & 48. \\
\hline & 5 & 3 & 4 & 5 & 5 & 5 \\
\hline ROTA 3 & $6 \%$ & $6+Y Y 2$ & 3.6 & AZ YOĞUN & düzenlemiş, araç yolu & 52 \\
\hline
\end{tabular}

Şekil 21: Rota özellikleri ve alt ölçütlere göre kriterlerin puanlanması 


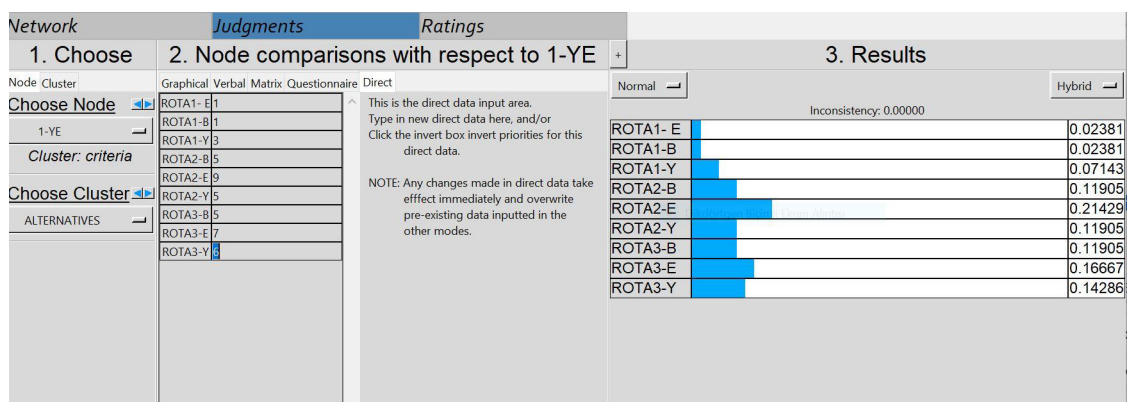

Şekil 22: Kriterlere göre rota puanlamalarının SuperDecision programına aktarılması

\section{Bayes Ağı ile Kriterlerin Ağırlıklarının Hesaplanması}

Bu koşullu olasılıklar sonucu tüm dügümlerin ağırlık yüzdeleri ise GeNIe tarafından hesaplanmıştır ve kriterler Analitik Hiyerarşi Süreci ile değerlendirilmek üzere SuperDecision programına aktarılmıştır. Örnek senaryo incelendiğinde; A kişisi o anki rota seçimi için mevcut modunun, \%20 maceracı, $\% 40$ aceleci, \%20 sportif, \%10 ise gezgin olduğunu belirtmiştir. Bu veriler GeNIe programında Bayes A ğı'na girildiğinde, her düğüme girilmiş olan eğitici veri seti doğrultusunda program her bir kriter için ağırlık yüzdelerini çıkarmıştır. Yani bir kullanıc \%20 maceraci, \%40 aceleci, \%20 sportif, \%10 ise gezgin olduğu için kriterlerinde yol genişliği \%12, yol eğimi \%17, süre \%19, yoğunluk \%12, kentsel tasarım \%52 ve çevre etkisi \%9 önemli olarak hesaplanmıştır (Şekil 23). Yapılan anket sayısının artması ya da bu veri setinin oluşması için sosyal medya verilerinden bilgi alınması öğretici veri setini iyileştireceği için, kriterlerin önem yüzdeleri değişken kullanıcı moduna daha duyarlı hale gelecektir.

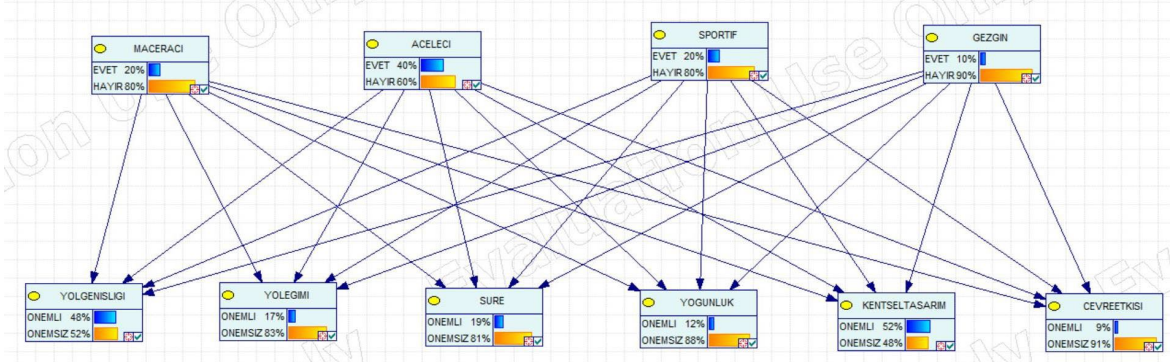

Şekil 23: GeNIe Programında değişken modların yüzdelerine göre hesaplanan kriterlerin ağırlık yüzdesi 


\section{Kullanıcının Moduna Göre Kullanıcıya Uygun Rotanın Belirlenmesi}

GeNIe programında, kullanıcının değişken moduna göre girilen yüzdeler sonrasında kriterlerin ağırlık yüzdeleri hesaplanmıştır. Bu yüzdeler SuperDecision programında bir A kullanıcısı için oluşturulan alternatif karar modeline aktarılmıştır (Şekil 24). Bu modele aktarılan kriterlerin önem yüzdelerine göre rota puan değerleri ile öneri rota tercihi yapılmıştır (Şekil 25). SuperDecision programında Analitik Hiyerarşi Süreci ile değişen yüzdeliklerin, kriterlerin önemini de değiştirdiği görülmektedir. Yapılan çalışmanın tutarsızlık raporu incelendiğinde bu oran 0,1 'in altındadır çünkü kriterler sabit puanlar ve önem yüzdeleri girilerek karşılaştırılmıştır. A kullanıcısının değişken moduna göre, Bayes Ağları ve Analitik Hiyerarşi Süreci ile GeNIe ve SuperDecision programlarında oluşturulan modelin önerdiği ulaşım seçeneği, Rota 2 ve E-scooter olarak belirlenmiştir (Şekil 26).

\begin{tabular}{|c|c|c|c|c|c|c|}
\hline goals & 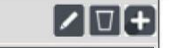 & criteri & 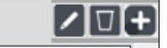 & ALTERN & JES $\triangle[$ & \\
\hline$A$ & 人回 & $1-Y E$ & CO & ROTA1- $E$ & 八D & \\
\hline & & $2-Y G$ & ㄷㅁ & ROTA1-B & ㅁㅁ & \\
\hline & & $3-5$ & 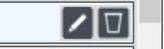 & ROTA1-Y & 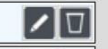 & \\
\hline & & $4-Y$ & ㄷㅁ & ROTA2-B & 미 & \\
\hline$\Theta$ & Add Node... & $\theta$ & Add Node... & $\theta$ & Add Nod & \\
\hline
\end{tabular}

Şekil 24. A kullanıcısının SuperDecisionda oluşturulan, kriterler ve alternatif karar modeli

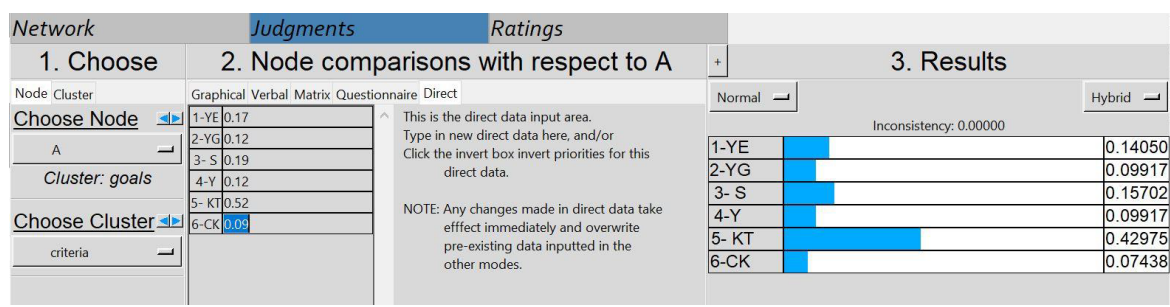

Şekil 25. A kullanıcısının değişken moduna göre belirlenen kriter yüzdeleri 


\begin{tabular}{|l|l|l|l|l|}
\multicolumn{3}{c}{$\begin{array}{l}\text { Here are the overall synthesized priorities for the } \\
\text { alternatives. You synthesized from the network Main } \\
\text { Network: DENEME10.sdmod: formulaic: ratings }\end{array}$} \\
\hline \hline \multicolumn{1}{|c|}{ Name } & Graphic & Ideals & Normals & Raw \\
\hline ROTA1-E & & 0.939428 & 0.146549 & 0.073274 \\
\hline \hline ROTA1-B & & 0.417142 & 0.065073 & 0.032537 \\
\hline ROTA1-Y & & 0.972735 & 0.151744 & 0.075872 \\
\hline \hline ROTA2-B & & 0.858065 & 0.133856 & 0.066928 \\
\hline \hline ROTA2-E & & 1.000000 & 0.155998 & 0.077999 \\
\hline \hline ROTA2-Y & & 0.818011 & 0.127608 & 0.063804 \\
\hline \hline ROTA3-B & & 0.708172 & 0.110473 & 0.055237 \\
\hline \hline ROTA3-E & & 0.514780 & 0.080304 & 0.040152 \\
\hline \hline ROTA3-Y & & 0.182017 & 0.028394 & 0.014197 \\
\hline
\end{tabular}

Şekil 26. A kullanıcısının değişken moduna göre modelin önerdiği ulaşım seçeneği

\section{Sonuç ve Öneriler}

Çalışmanın amacı iki kamusal alan arasında mikromobiliteyi ve yürünebilir rotaların oluşturulmasını destekleyen kişiselleştirilmiş bir model geliştirilmesidir. Çalışmada farklı kullanıcı tiplerinin değişen tercihlerine göre, farklı rotalarda, farklı ulaşım seçeneklerinin sunulabilmesi için bir karar destek sistemi önerilmiştir. Bu çalışma ile kent içinde bireysel kullanıma yönelik, çevreci ve kullanıcı odaklı ulaşım rotaları oluşturulması ve kent içi bireysel ulaşım seçenekleri için kullanıcıya yardımcı bir sistem sunulması hedeflenmektedir. Yöntem olarak Analitik Hiyerarşi Sürecinin içine Bayes Ağları'nın dahil edilmesi kullanıcıların kriterleri değerlendirme sürecini hızlandırmış ve kullanıcıların değişken mod birlikteliklerinin bir arada olma olasılığına göre kriterlerin kendiliğinden ağırlıklandırılmasını sağlamıştır.

Kamusal alanların erişilebilirliğini hem çevreci bir yaklaşım ile hem de sosyal ilişkiler ölçeğinde incelediğimizde ayn kullanıcının bile farklı zamanlarda farklı ulaşım seçeneklerini tercih edebilmesi, kullanıcıya esneklik sağlamakta ve uzun vadede kentteki ulaşım alışkanlıklarını değiştirebilir bir yaklaşım sunmaktadır. Çalışma kamusal alanların ulaşılabilirliğini mikromobilite destekli hale getirirken aynı zamanda farklı kullanıcıların farklı taleplerine göre önerilen ulaşım seçenekleri kamusal alanlardaki farklı kullanıcıları karşılaştırmaktadır. Bu kişiselleştirilmiş ulaşım modeli ile, kullanıcılar otomobil egemen dünyanın sınırlarındırıcılı̆̆ına göre daha kişisel ve gündelik 
taleplerine uygun rotalara yönlendirilebilmektedir. Bu model ile kamusal alanların herkesin tercihlerine göre daha erişebilir olabileceği ve yeşil sistemin içinde daha sürdürülebilir hale geleceği öngörülmektedir.

Çalışmanın geliştirilmesi sürecinde veri madenciliği çalışmaları da modele dahil edilip, kullanıcıların sosyal medya verileri, dinledikleri müzikler ya da tweetlerde tespit edilen içerikler ya da Instagram görüntülerinin işlenmesi ile birlikte mod seçimi sağlanabilir ve ulaşım seçenekleri de buna göre tavsiye edilebilir. İnstagram kullanımının kamusal alan üzerinde yarattığ algı nedeni ile kamusal alan kullanımında Instagram görselleri çok fazla yönlendirici olmaktadır. Bu nedenle çalışmanın devamında modların değişken sınıflarının belirlenme sürecinde instagram verileri üzerinden makine öğrenmesi ile geliştirilmesi öngörülmektedir. Bu kapsamda model, kullanıcıların kendilerinin mod seçimi yapmasına gerek kalmadan modların ve bu modlar sonrasında da yine Bayes Ağları ve Analitik Hiyerarşi Süreci ile rotaların tavsiye edildiği bir karar destek sistemine dönüş̧ebilir.

Gelecekte kentsel tasarım ve ulaşım planlama projelerinde disiplinlerarası çalışmaların gerekliliği aşikardır. Bu çalışma kamusal alan kullanımı, kişiselleştirilmiş ve çevreci ulaşım seçenekleri ve makine öğrenmesi gibi farklı disiplinlerin kesiştiği bir alan yaratmaktadır. 


\title{
Extended Abstract
}

\section{Personalized Transportation Model Proposal to Support Micromobility Between Public Spaces}

\author{
Esma Selen Aksoy ${ }^{7}$ \\ ORCID: 0000-0002-8373-9737
}

\author{
Şehnaz Cenani ${ }^{8}$ \\ ORCID: 0000-0001-8111-586X
}

\author{
Gülen Çağdaş ${ }^{9}$ \\ ORCID: 0000-0001-8853-4207
}

\section{Introduction and Research Questions \& Purpose:}

Public spaces are a meeting point in the city, where different individuals meet and spend time together. Transportation options to these areas may not always be the same due to the changing demands of individuals. It is also very important that the preferences are not the same and not directed to the same option in order to ensure diversity in the use of public space. For this reason, in the study, a personalized transportation model between two public spaces is proposed, considering that public spaces are important points in the city. The aim of the study is to create a personalized transportation preference model that supports micromobility among public spaces. With this model, a decision support system will be presented to the user in the selection of environmentally friendly and user-oriented transportation routes for individual use in the city.

\section{Literature Review}

As stated by Gehl (2006), the accessibility of public spaces with each other is also important in terms of the formation of ecological green bridges and the

\footnotetext{
${ }^{7}$ Doktora Öğrencisi, İTÜ, E-mail: aksoye@itu.edu.tr

${ }^{8}$ Dr. Öğr. Üye., İstanbul Medipol Üniversitesi, E-mail: sdurmazoglu@medipol.edu.tr

9 Prof. Dr., İTÜ, E-mail: cagdas@itu.edu.tr

idealkent @ Kent Araştırmaları Dergisi (Journal of Urban Studies) 
transfer of social relations. Suggesting the same routes to users while accessing these areas limits the users' access options to the public space. Therefore, in this study, a decision support system is presented where different transportation options are offered to different users. As Cimler (2013) stated in his studies, many situations affect the decision in models developed with the Analytical Hierarchy Process used in the selection of vehicles or routes of different user profiles. Studies conducted with systems in which the status of drivers in traffic are classified as patient, impatient, experienced or inexperienced has laid the groundwork for the discussion of different driver types and criteria (Cimler, 2013). In addition, socio-economic factors also affect the choice of transportation vehicle and route (Amine,2018). However, the decision support systems offered generally focus on providing the fastest or most reasonable route. The aim of this study is to determine the preference possibilities in different situations, rather than just choosing the most appropriate route.

It is known that the Analytical Hierarchy Process can use the probabilities obtained by the Bayes formula to increase the accuracy of input data (Saaty and Vargas, 1998). Bayes Theorem has been used to obtain aposteriori probabilities, that is, relative probabilities in the work of Stanković and Milić (2015). The importance of the criteria that will predict the activities of the company has been evaluated together with different strategy possibilities. The priorities of the criteria in the Analytical Hierarchy Process have also been determined according to these possibilities. In the studies examined, it has been observed that Bayesian Networks are also used in product selection estimation of different users. In a study by Ji-Chun Quan and Sung-Bae Cho (2014), a smart TV program proposal method is presented for multiple users using Bayesian Networks and Analytical Hierarchy Process. In line with these studies, in the proposed model, Bayesian Networks were included in the Analytical Hierarchy Process in order to obtain the importance percentages of the criteria according to the preferences of the users.

\section{Method}

Analytical Hierarchy Process and Bayesian Networks are used as methods in the study. The transportation options that will be evaluated in the Analytical Hierarchy Process method are discussed within the scope of micromobility studies. Bayes Networks have been preferred in determining the importance of the criteria that are effective in selecting these routes, in order to increase the accuracy of the input data in the Analytical Hierarchy Process, to change 
the importance level of the criteria according to the variable mode of the users and to make the system more flexible. E-scooter, bicycle and walking options and routes suitable for these options were determined to support micromobility between two public spaces. Then, the criteria that affect the users in the process of deciding on one of the routes between the two selected areas were determined. These criteria are also evaluated by variable users in the Bayesian Network. In the study, three routes between two public spaces have been chosen to create an exemplary model. These routes are reserved as a different alternative for each transportation option. After determining nine different transportation preferences with three routes and three transportation options selected for the project sample scenario, the routes were scored according to the determined criteria. For the criteria that will determine the appropriate transportation preferences for the routes, literature studies on bicycle, escooter and walkability have been made and the suitability of the routes was scored by taking some threshold values.

Bayesian Networks and AHP are carried out from two different branches in the same process. In the Bayesian Networks section, it is primarily aimed that users can use the route preference system most easily and effectively. Through Bayesian Networks, it can be calculated how the users will determine the importance of the criteria that will affect their preferences in different modes or when different modes are together. To determine the importance values of different users to different criteria, Causal Bayesian Networks were selected based on expert opinion.

In the study, the Causal Bayesian Network was created in which the criteria are defined as nodes and the variable user modes are parents. In order to evaluate the coexistence of different user modes with different probabilities of the criteria determined in the Causal Bayesian Network, a web-based survey was created. In this survey, users were asked which criteria they would consider when they were in different modes. Then, the data obtained were combined and transferred to conditional probability tables. These tables were transferred to the nodes in the Causal Bayes Network environment, created through the GeNIe program. With this method, after the data set prepared as a result of the survey, the change of the percentage of different modes and the calculation of different weight percentage for each criterion that will determine the route and transportation vehicle, flexibility in the decision support system is provided. In the sample scenario created with this flexibility, the percentages of the criteria determined according to the user's mode were transferred to the SuperDecisions program to be evaluated by AHP, where 
different transportation preferences were compared with the binary comparison method.

\section{Results}

As a result of this study, a recommendation system model has been created in which variable routes are suggested to different users according to their changing demands in daily life. Determining the weights of the criteria according to the modes in line with the conditional probabilities in the data set enabled the criteria to be weighted automatically according to the probability of the variable mode associations of the users with including Bayesian Networks in the Analytical Hierarchy Process as a method. The proposed model will provide the most suitable route to be recommended by rapidly evaluating many criteria by choosing certain modes instead of evaluating the criteria such as traffic density, physical and environmental conditions of the routes one by one. In future studies, in the creation of the educational data set in which the weights of the criteria are determined according to the different modes of the users, the mode selection can be developed by including the data mining studies in the model and can be made recommendations accordingly.

\section{Kaynakça/References}

Bayesfusion (2020). 12 Kasim 2020 tarihinde https://www.bayesfusion.com adresinden erişildi.

BikeRoll. (2020). BikeRoll. 6 Mayıs 2020. https://bikeroll.net/tr adresinden erişildi.

Boy, J. D., ve Uitermark, J. (2016). How to study the city on Instagram. PLOS One, 11(6), 612 - 624. doi:10.1371/journal.pone.0158161

Cimler, R. (2013). Analytic hierarchy process and agent-based simulation for traffic modeling. 12. Uluslararası Analitik Hiyerarşi Süreci Sempozyumu'nda sunulmuş bildiri metni, Kuala Lumpur, Malaysia. doi: 10.13033/isahp.y2013.022

Cheliotis, K. (2019). Agent-Based Modelling of Public Space Activity in Real-Time (Doktora tezi). $\quad$ https://www.researchgate.net/publication/331770554_AgentBased_Modelling_of_Public_Space_Activity_in_Real-Time\#fullTextFileContent adresinden erişilmiştir.

Çinicioğlu, E.N., Ekici, Ş.E., ve Ülengin, F. (2015). Bayes ağ yapısının oluşturulmasında farklı yaklaşımlar: Nedensel Bayes ağları ve veriden ağ öğrenme. Sn. Prof. Dr. Halil Sarıaslan'a Armağan Kitabı içinde (s. 267-284), Ankara: Siyasal

Kitabevi.

https://openaccess.dogus.edu.tr/xmlui/bitstream/handle/11376/2695/onsel_2015_t .pdf?sequence $=1$ \&isAllowed $=\mathrm{y}$ erişilmiştir. 
Dereli, B. (2012). Bayes ağları ile gelecek odaklı konumlandırma analizi: oyun konsolları $\begin{array}{llll}\text { pazarında bir uygulama. (Yüksek lisans } & \end{array}$ tezi). https://polen.itu.edu.tr/bitstream/11527/5766/1/12349.pdf adresinden erişilmiştir.

Dotoli, M., Zgaya, H., Russo, C., ve Hammadi, S. (2017). A multi-agent advanced traveler information system for optimal trip planning in a co-modal framework. IEEE Transactions on Intelligent Transportation Systems, 18(9), s. 23972412. doi: 10.1109/TITS.2016.2645278

El Amine, S. (2018). Agent-based modeling of the social and economic factors affecting the choice of transportation mode: Application to the Beirut city (Doktora tezi). https://www.researchgate.net/publication/331987968_Agent-

based_modeling_of_the_social_and_economic_factors_affecting_the_choice_of_t ransportation_mode_application_to_the_Beirut_city adresinden erişilmiştir.

Food4rhino (2020). 12 Kasim 2020 tarihinde, https:/www.food4rhino.com/app/mosquito-media-4-grasshopper adresinden erişildi.

$\mathrm{Hu}, \mathrm{Y} .$, Manikonda, L., ve Kambhampati, S. (2014). What we Instagram: A first analysis of instagram photo content and user types. 8. ICWSM'de yayınlanmış bildiri, (s. 595 598). California: The AAAI Press. https://scinapse.io/papers/84786028 adresinden erişilmiştir.

Küçükpehlivan G., ve Doğru, A. (2017). Bisiklet yolu güzergâhlarının ahy ile kullanıcı odaklı olarak belirlenmesi. Harita Dergisi, 83(157), 1-8. https:/www.harita.gov.tr/images/dergi/makaleler/4b7591879ca3f83.pdf adresinden erişilmiştir.

Mimović, P., Stankovic, J., ve Milić, V.J. (2015). Decision-making under uncertainty the integrated approach of the AHP and Bayesian analysis. Economic ResearchEkonomska Istraživanja, 28(1), 868- 878. doi: 10.1080/1331677X.2015.1092309

Norsys (2020). 12 Kasım 2020 tarihinde, https://www.norsys.com adresinden erişildi. Öztaş, Ç., İmamoğlu, C., Akı, M., ve Üzümoğlu, T. (2016). Bölgesel güvenli bisiklet yolları uygulama projesi Tekirdağ. https://www.trakyaka.org.tr/upload/Node/33078/xfiles/Trakya_Bolgesi_Bisiklet_ Yollari.pdf adresinden erişilmiştir.

Pearl, J. (1982). Reverend Bayes on inference engines: A distributed hierarchical approach. 2. AAAI Konferası'nda yayınlanmış bildiri, (s. 133 - 136). California: The AAAI Press. https://aaai.org/Papers/AAAI/1982/AAAI82-032.pdf adresinden erişilmiştir.

Pearl, J. (2000). Causality: Models, Reasoning and Inference, Cambridge: MIT Press.

Ravazzoli, E., ve Torricelli, G. P. (2017). Urban mobility and public space: A challenge for the sustainable liveable city of the future. The Journal of Public Space, 2(2), 37-50. doi: 10.5204/jps.v2i2.91 
Saaty, T.L. (2000). Fundamentals of Decision Making and Priority Theory with the Analytic Hierarchy Process (Analytic Hierarchy Process Series, Vol. 6), Pittsburgh: RWS Publications.

Saaty, T., ve Shih, H-S. (2009). Structures in decision making: On the subjective geometry of hierarchies and networks. European Journal of Operational Research, 199(3), 867-872. doi: 10.1016/j.ejor.2009.01.064

Saaty T., ve Vargas, L. (1988). Diagnosis with dependent symptoms: Bayes theorem and the analytic hierarchy process. Operations Research, 46(4), 491-502. https://pubsonline.informs.org/doi/abs/10.1287/opre.46.4.491 adresinden erişildi.

Silva, O., Amoêdo, N., ve Almeida, F. (2019). Urban tourist motivations in the city of Porto,

Ottoman: Journal of Tourism and Management Research,4(2), 445-462. doi: 10.26465/ojtmr.2018339521

Superdecisions (2020). 12 Kasım 2020 tarihinde, http://www.superdecisions.com adresinden erişildi.

Uz, V. E., ve Karaşahin, M. (2004). Kent içi Ulaşımda Bisiklet. Türkiye Mühendislik Haberleri, 49(429), 41-46. http://www.imo.org.tr/resimler/dosya_ekler/613d551d4160a60_ek.pdf?dergi=166 adresinden erişildi.

Yücebaş, S. C., (2006). Hipokrat-I: Bayes ă̆ı tabanlı tıbbi teşhis destek sistemi.

(Yüksek Lisans Tezi). http://dspace.baskent.edu.tr:8080/xmlui/handle/11727/1434 adresinden erişildi.

Xiana, H. (2017). Simulation of Pedestrian Flow in Traditional Commercial Streets Based on 